Child Development, 1969, 40, 969-1025

\title{
OBJECT RELATIONS, DEPENDENCY, AND ATTACHMENT: A THEORETICAL REVIEW OF THE INFANT-MOTHER RELATIONSHIP
}

\author{
MARY D. SALTER AINSWORTH
}

Johns Hopkins University

3 theoretical approaches to the origin and development of the infant-mother relationship are reviewed: psychoanalytic theories of object relations, social learning theories of dependency (and attachment), and an ethologically oriented theory of attachment. "Object relations," "dependency," and "attachment," although overlapping, are seen to differ substantially. Among the concepts in regard to which there are significant intertheoretical differences, the following are discussed: genetic "biases," reinforcement as compared with activation and termination of behavioral systems and with feedback, strength of attachment behavior versus strength of attachment, inner representation of the object, intra-organismic and environmental conditions of behavioral activation, and the role of intra-organismic organization and structure. Finally, the relation between theory and research methods is considered.

Three terms have been commonly used to characterize the infant's relationship with his mother: "object relations," "dependency," and "attachment." Although they overlap somewhat in their connotations, these terms are not synonymous. Each is more or less closely tied to a distinctive theoretical formulation of the origin and development of early interpersonal relations.

The concept of object relations stems from psychoanalytic instinct theory. The "object" of an instinct is the agent through which the instinctual aim is achieved, and the agent is usually conceived as being another person. It is generally agreed that the infant's first object is his mother. The origin of object relations lies in the first year of life, and most, although not all, psychoanalysts have viewed the infant's initial relationship with his mother as being essentially oral in nature. The major theoretical division, however, is between those who hold that there are at least prototypical object relations from the beginning and those who hold that "true" object relations grow out of and supplant the infant's earlier dependency relationship with his mother.

Although the term dependency has been used by some psychoanalysts to characterize the infant's preobjectal relations, it is especially linked to social learning theories. These theories follow the psychoanalytic lead in conceiving the origin of interpersonal relations to lie in the infant's dependence on his mother. (Although "dependency" and "dependence" may be used interchangeably, "dependency" has been preferred as a 
technical term in scientific and professional writing.) Dependency was defined at first as a learned drive, acquired through its association with the reduction of primary drives. Dependency could become a generalized personality trait, in regard to which there were individual differences, presumably reflecting different learning histories. Or, more recently, dependency has been viewed by learning theorists as a class of behaviors, learned in the context of the infant's dependency relationship with his mother, and reinforced in the course of her care of him and interaction with him. In any case, although the first dependecy relationship is a specific one-with the mother or mother substitute dependency is viewed as generalizing to other subsequent interpersonal relations and to be commonly nonspecific in its implications. Dependence connotes a state of helplessness. Behavior described as dependent implies seeking not only contact with and proximity to other persons but also help attention, and approval; what is sought and received is significant, not the person from whom it is sought or received. Dependency in the psychoanalytic context also has nonspecific implications, but object relations once acquired are considered sharply specific.

Dependence implies immaturity, and, indeed, the term is the antonym of "independence." Although normal in the young child, dependence should gradually give way to a substantial degree of independence. And yet it may be observed that relationships to specific persons-whether termed "object relations," "attachments," or "dependency relationships"-develop concurrently with the development of the competencies upon which independence is based. Recognizing this paradox, some social learning theorists (e.g., Beller 1955; Heathers 1955) have disclaimed a bipolar dimension of dependence-independence, but this disclaimer leaves the term "dependency" a misleading one.

Occasionally, psychoanalytic writers from Freud onward have used the term attachment when referring to specific love relations. Its current use in the psychological literature stems, however, from Bowlby (1958). In the course of proposing a new approach to the origins of a child's tie to his mother, a theory based on ethological principles, Bowlby sought a term to replace "dependency"-a term free of the theoretical connotations that "dependency" had accumulated, The term "attachment" then gained usage with some ethologists and spread from them to psychologists studying animal behavior and thus to some contemporary learning-theory formulations.

"Attachment" refers to an affectional tie that one person (or animal) forms to another specific individual. Attachment is thus discriminating and specific. Like "object relations," attachments occur at all ages and do not necessarily imply immaturity or helplessness. To be sure, the first tie is most likely to be formed to the mother, but this may soon be supplemented by attachments to a handful of other specific persons.

Once formed, whether to the mother or to some other person, an attachment tends to endure. "Attachment" is not a term to be applied to any transient relation or to a purely situational dependency transaction. Dependency relations vary according to the exigencies of the situation. Attachments bridge gaps in space and time. To be sure, attachment behavior may be heightened or dampened by situational factors, but attachments 
themselves are durable, even under the impact of adverse conditions. (The same enduring quality is attributed by psychoanalysts to "object relations.") This implies the formation of intra-organismic structures, presumably neurophysiological in nature, which provide the person with a continuing propensity to direct his attachment behaviors toward specific objects of attachment.

It is the purpose of this paper to review the corpus of theory that has accumulated in regard to each of these three terms. For convenience, the review will be ordered as follows: (a) psychoanalytic theories of object relations, (b) social learning theories of dependency and attachment, and (c) an ethological approach to attachment. Except for passing reference crucial to the comparison and evaluation of the theoretical formulations, pertinent research evidence cannot be reviewed here.

\section{PSYCHOANALYTIC THEORIES OF OBJECT RELATIONS}

According to Freud's instinct theory, an instinctual drive has a source and an aim, both of which are genetically determined and hence little influenced by environmental variations-and also an object, the means through which the aim is achieved, which is variable and environmentally labile (S. Freud [ 1914] 1957, pp. 122-123) . In 1905 (1953) Freud specified that the child's first love object is the mother's breast, and he referred to the early suckling relationship as the prototype of all later love relations. Even in this first statement, however, he broadened the basis of this earliest of relations beyond orality. The mother, in stroking, kissing, and rocking the baby, is fulfilling her task "in teaching him to love" (p. 222). In 1914 Freud characterized the first object relation as "anaclitic"-because he viewed the sexual instincts, in this phase of development, as finding their satisfaction through "leaning on" the self-preservative instincts (p. 87). The implication is that anaclitic love depends chiefly upon being fed. Later (1926) he observed that the infant experiences anxiety when his mother is absent or seems about to go. He identified this as "signal" anxiety; separation signals the danger to the child that his bodily needs will go unsatisfied ([1926] 1959, pp. 136-138).

It was not until 1931 that Freud came to a full recognition of the enduring significance of infant-mother attachment (S. Freud [1931] 1961), and this he reiterated in 1938 when he designated the mother's importance as "unique, without parallel, established unalterably for a whole lifetime as the first and strongest love-object and as the prototype of all later love relations" (1938, p. 188) . He then reviewed his earlier statements, but at the end of his discussion introduced a new concept. "The phylogenetic foundation has so much the upper hand . . . over accidental experience, that it makes no difference whether a child has really sucked at the breast or has been brought up on the bottle and never enjoyed the tenderness of a mother's care. In both cases the child's development takes the same path; it may be that in the second case its later longing grows all the greater (1938, pp. 188-189) .

Freud's account, although unequivocal in regard to the significance of the infant-mother tie, was incomplete, scattered, and somewhat contradictory. Consequently, it left room for theoretical division in subsequent psychoanalytic theory concerned with the origins and development of this tie. In one tradition are theorists who follow Freud's emphasis on the 
lability of objects and his view that the infant acquires the mother as object through his dependence on her for need-gratification. This group of theorists views the development of object relations as being inextricably intertwined with ego development, and thus as being dependent on the acquisition of cognitive structures not present at the beginning. This is the tradition of "ego psychology." The other group of theorists, implicitly or explicitly picking up Freud's reference to a "phylogenetic foundation," views object relations as primary rather than secondary and acquired. This tradition is self-designated as "object relations theory."

\section{Ego Psychology}

The ego psychologists, while accepting Freud's theory of psychosexual development, have emphasized the development of object relations in the context of the development of ego functions-a view relatively little elucidated by Freud. Although there are some differences from one theorist to another, there is a substantial core of agreement among them. The ensuing account is a very condensed summary of the following: Benedek (1952) ; Escalona (1953); Anna Freud (1946, 1952, 1954, 1965) ; Greenacre (1960); Hartmann, Kris, and Loewenstein (1946, 1949); Hoffer (1949, 1950) ; Kris (1951, 1955) ; Mahler (1952, 1963, 1965) ; Mahler and Cosliner (1955) ; and Spitz (1957, 1959, 1965a, 1965b) .

There is general agreement that the newborn is an almost wholly undifferentiated organism-undifferentiated structurally, topographically, and dynamically. Neither id nor ego have yet emerged from their common, undifferentiated core, and distinctions between conscious, preconscious, and conscious processes are irrelevant, if, indeed, they can be made at all. The baby cannot discriminate between things in his environment, norbetween person and thing. Indeed he cannot even distinguish himself from his environment-which implies that he cannot discriminate between sensory input from his own body and sensory input from the external world. Because of this discriminative failure, the newborn is described as experiencing everything as part of himself-and it is held, therefore, that all of his libidinal energy is contained within himself. His experience varies between states of tension (which have the affect of unpleasure) and states of relative quiescence. Since the baby cannot even distinguish his mother from himself, he cannot relate to her as an "object"-that is, a love object. He is aware of very little else but the ebb and flow of his own tensions, being protected by a high stimulus barrier from environmental impingements. This first period of life is characterized by what Freud called "primary narcissism"; others label this first period as "undifferentiated" or "objectless."

Within a relatively short period of time-somewhat less than 12 months-the infant will have undergone profound transformations. Ego functions will have emerged. The baby will be able to distinguish between self and non-self; his passivity will have given way to active engagement with the external world; he will have achieved a substantial degree of competence; and he will make clear-cut distinctions between people, have definite preferences, and under ordinary conditions he will have formed a firm attachment to his mother. There is substantial agreement among the ego psychologists as to the main steps in this transformation and as to the processes which play a part in it, although there are some differences in emphasis. 
In general, the development of object relations is viewed as going through three main stages: (1) an undifferentiated or objectless stage, (2) a transitional stage, and (3) a stage of object relations.

The undifferentiated, narcissistic, or objectless stage.-In emphasizing the undifferentiated nature of the newborn, the ego psychologists do not claim total lack of differentiation. All acknowledge constitutional "givens" or Anlage, which are genetically determined beginnings of more complex processes which will mature later. But they view the newborn's responses, even the most complex, as tied to visceral, autonomic, emotional organizations rather than to organizations based on perceptual discrimination of the environment.

Anna Freud, even more explicitly than the others, tied the origin of object relations to need-gratification, with particular emphasis on the feeding relationship. The affective experience of the infant includes not only the unpleasure of tension but also the positive pleasure associated with the relief from tension. The libidinal cathexis during this early period is attached, not to the mother or even to the breast as object, but to the "blissful experience of satisfaction and relief" (A. Freud 1954). When the baby is not in a state of tension he is self-centered and self-sufficient, that is to say, narcissistic-but when under the pressure of urgent bodily needs, specifically hunger, he "periodically establishes connections with the environment which are withdrawn again after the needs have been satisfied and the tension is relieved." These first occasions of wish fulfillment and pleasure "establish centres of interest to which libidinal energy becomes attached." This implies that at first the infant does not love his mother, but has cathected the experience of feeding. "An infant who feeds successfully 'loves' the experience of feeding" (A. Freud 1946).

Benedek (1952) described the following rhythmic course of events as characteristic of normal mother-infant interaction: arising need, disturbance of sleep, crying, gratification, and again sleep. In this phase of "extra-uterine symbiosis;" the mother is part of the process of gratification. Feeding not only satisfies hunger, but it conveys to the baby the tactile and kinesthetic feelings of having been protected; it preserves the security of the symbiosis.

The concept of symbiosis has been modified by the psychoanalysts from its original biological meaning of mutual dependence. Margaret Mahler (1965), for example, referred to the symbiotic, parasite-host relationship between fetus and mother in the prenatal period. During the early postnatal period-which Mahler differentiated into the phase of "normal autism" and the "symbiotic" phase-the baby is described as being in a "symbiotic envelope." Her discussion highlights the fact that for this group of psychoanalytic theorists the primary task of the baby is to become separate from his mother-to hatch-rather than to become attached to her.

The transitional stage.-This is a period between the undifferentiated first stage and the stage in which clear-cut object relations are finally established. During this transitional period certain ego functions develop, and one can speak of a primitive "body ego." 
Distance receptors become more important. Memory traces are laid down. Certain kinds of directed behavior emerge. Some distinction can be made between self and non-self, although this is by no means complete, and the infant is still viewed as being incapable of cathecting a true object.

For Anna Freud (1946) the relationship between child and mother is still "anaclitic"-it still depends upon the need for food. But the baby moves a step from his earlier cathexis of the experience of need-satisfaction, to a cathexis of the food which is the source of pleasure. "The infant in this second stage `loves' the milk, breast or bottle."

Spitz (1965a) sharply distinguished the beginning of the second stage-which he called the stage of the "precursor of the object"-by the emergence of the smiling response which he considered a species-specific response to the human face. This does not imply cathexis of the face, for the smile is indiscriminate at this stage. But the smiling response is the behavioral indicator of an inner shift from an interoceptive, autonomic organization of input to a more differentiated, perceptual organization in which the distance receptors play an increasingly important role. This inner reorganization makes it possible for the ego to form and for social relations to begin. Nevertheless, Spitz emphasized need-gratification. The smiling response is viewed as an affective sign of expected gratification. Crying when the mother leaves is another affective indicator; her departure signals an expectation of mounting need-tension.

Other theorists do not so sharply distinguish the beginning of the second stage. They place the shift from narcissism at different times and suggest different behavioral indices to mark it. Hoffer $(1949,1950)$ considered that voluntary thumb-sucking indicates the emergence of the ego-at about 12-16 weeks of age. Anna Freud (1954) and Kris (1951) attached special significance to the ability to anticipate the feeding situation and to wait for it. Benedek (1952) identified a sequence of behaviors as reflecting gradual development-the infant's finding his mouth to suck his fingers, following his mother with his eyes, turning his head to smile at the mother expectantly, and having the ability to wait while watching the preparations for his feeding. If this developmental process goes well the baby gains a sense of confident expectation that his needs will all be satisfied. This "confidence" is the psychic correlate of his passive, receptive, dependent stage. It acts as an "emotional shelter" and facilitates learning, for the baby can turn attention from his inner instinctual tensions toward the environment. Erikson $(1950,1959)$, who borrowed this concept from Benedek, termed it "basic trust."

Escalona (1953), while concerned with many of the core developmental problems of the ego psychologists, gave much less emphasis than the others to need-gratification. She contended that mother-infant transactions such as reciprocal smiling, babbling, and play might become pleasurable in their own right. Addressing herself to the problem of distinction between self and non-self, Escalona did not conclude that directed activity such as voluntary thumb-sucking or smiling at the mother are proper indices. She followed Piaget ([1936] 1952) in proposing that changes the infant brings about through his own action may be experienced by him as mere changes of state and not as contingent upon his actions. Conscious, purposive, goal-directed action and expectation depend upon some 
experience of feeling separated from the goal in space and time; and, similarly, separation between self and non-self implies some experience of distance. Therefore, she suggested a more gradual emergence of the self- non-self distinction. Throughout the first 6 months or so, the baby's "awareness of an outer world in which things happen can rise and submerge," and "the boundary of the self may shrink and expand in peculiar ways." Gradually, "islands of consistency" emerge in the baby's experience, in which he feels himself as either an active or passive agent of some change-but this growing distinction may be "temporarily drowned out on many occasions."

True object relations.-Anna Freud (1965) defined this stage as "the stage of object constancy, which enables a positive inner image of the object to be maintained, irrespective of either satisfactions or dissatisfactions." The baby now clearly perceives his mother as a person separate from himself. No longer do his libidinal cathexes come and go in accordance with his need state. Now he is capable of maintaining his tie to her, irrespective of his need state, and regardless of whether she is currently being gratifying or frustrating, and whether she is present or absent-although the object cathexis is still too fragile to be sustained over very long absences. When the mother leaves, she is not forgotten. The child has some internalized representation of her that persists. Even though his needs may be gratified while she is absent, he misses her and is distressed.

Anna Freud (1946) distinguished the beginning of the stage of object love-true object relations-as follows: "When its powers of perception permit the child to form a conception of the person through whose agency it is fed, its 'love' is transferred to the provider of food." She continues: "The infant's first love for the mother is directed toward material satisfaction. (Stomach love, cupboard love, egoistic love; 'to be fed.')" She distinguished this early stage of true object relations from a second, later one in which "object love is still egoistic but directed toward nonmaterial satisfactions, i.e. to receive love, affection, approval from the mother; 'to be loved."' At this point, she suggested (1952 ), the baby, no longer as need dominated as before, does not when separated from his mother shift his attachment within several days to substitute figures from whom he gains gratification, but is distressed for a longer time and has more difficulty in forming new attachments.

Spitz (e. g., 1959) marked the beginning of the stage of the "libidinal object proper" by the sudden emergence of an anxious response to strangers which he terms "eight-month anxiety." This response, which is most conspicuous when the mother is absent, was attributed to her absence. The baby perceives that the stranger is not his mother, concludes that his mother has left him, and is therefore anxious. To perceive that the stranger is not his mother implies a comparison of the strange face with memory traces of the mother's face. Since he now shows "the capacity of cathectic displacement on reliably stored memory traces;" we can be sure he is now capable of true object relations. "Before this we can hardly speak of love, for there is no love until the loved one can be distinguished from all others, and there is no libidinal object as long as it remains interchangeable" (Spitz 1965a, p. 156).

Hartmann et al. (1946) were particularly concerned with the interlocking between ego functions and object relations. They focused on what, to Anna Freud, was a second and 
later phase of development of "true object relations." They stressed the importance of the child's understanding of his mother's communications and termed this the "cognitive side of the process" which nevertheless is "part of the libidinal tie existing between the two." The gradual shift from pleasure principle to reality principle possible when the child can substitute anticipated future gratifications for immediate ones-is shown by his ability to conform to his mother's requests and prohibitions. When he can do this, he is clearly concerned with her love and with the threat of loss of love and not merely with loss of love object. If, when activity is restrained or gratification is delayed, the child can turn with interest toward the love object rather than responding aggressively to the frustration, the cathexis toward the gratifying action is transformed into object cathexis. Later (1949) these authors attributed the shift from fear of loss of object to fear of loss of love to the child's ability to "neutralize instinctual energies and to socialize their expression." (The concept of neutralization of instinctual energies is fundamental to Hartmann's [ (1939) 1958] theory of the autonomy of ego functions, which cannot be discussed here.)

A second phase of development of "true" object relations was also distinguished by Spitz (1957, 1965a) who marked its onset with an index related to the child's understanding of his mother's prohibitions. The index consists of negative head shaking, which is held to come about through a process of identification with the mother's control of the infant's behavior through "No! no!" accompanied by a shake of the head.

\section{Object Relations Theory}

Object relations theory, originating in the Hungarian school of psychoanalysis, led by Ferenczi, explicitly disavows the concept of primary narcissism and holds that there are object relations, albeit primitive ones, from the very beginning. This tradition, which has been more influential in Great Britain than in the United States, has in some respects greater compatibility with the ethological approach than has the tradition of "ego psychology." These theories present detailed and complex accounts of development throughout various stages of infancy and early childhood; the following comments are limited to their views on the origin of the infant-mother tie.

Melanie Klein (e.g., 1952) described babies who, as young as 3 weeks, interrupt their sucking to look at the mother's face, or, when perhaps 2 weeks older, respond to the mother's voice and smile with a change of facial expression, as indicating that "gratification is as much related to the object which gives the food as to the food itself" (p. 239). Nevertheless, her theoretical account of the earliest period of development is much dominated by themes of food, orality, and the breast. The baby's first object relation is held to be to "the loved and hated-good and bad-breast." She believed that the infant has an inborn. striving for the breast: "the newborn infant unconsciously feels that an object of unique goodness exists, from which a maximal gratification could be obtained and that this object is the mother's breast" (p. 265).

Michael and Alice Balint also held that a primitive object relation is present from the beginning. Michael Balint ( [1937] 1949) identified it as "something on its own" and not linked to any of the erotogenic zones. Alice Balint (11939] 1949) emphasized the instinct 
to cling as a significant part of this early object relation-and in this relation she saw the infant as active rather than passive as Ferenczi (1924) had suggested.

Winnicott $(1948,1953,1960)$ was not explicit about the origins of the infant-mother tie, but his discussion of mothering and the "good enough mother" make it clear that he did not give primary emphasis to orality. More important is physical holding, which he considered so basic a "form of loving" that he extended the term "holding" to cover the "total environmental provision" during the earliest period of development.

Fairbairn (1952), while emphasizing orality, disavowed primary narcissism, and insisted that instinctual drives have objects from the beginning. Later (1956) he protested against the "assumption that man is not by nature a social animal" and explicitly pointed to ethology as demonstrating that even the newborn manifests object-seeking behavior.

Bowlby (1958, 1969), a psychoanalyst in the tradition of object relations theory, not only opposed the view of interpersonal ties as secondary acquisitions which have developed on the basis of gratification of primary drives, but urged an updating of psychoanalytic instinct theory to a view congruent with present-day biology. The infant-mother tie is based on a number of species-characteristic behavioral systems which, from the beginning, are activated or terminated by classes of stimuli most likely to emanate from other persons, and which facilitate proximity and interaction of infant and mother. His formulation, however, will be considered in another section of this paper.

\section{Discussion}

In attempting to evaluate the contribution of psychoanalytic theory to an understanding of early infant-mother relations, it must be noted that attention is given chiefly to a reconstruction of what the experience of the baby is most likely to have been during the successive stages of the first developmental epoch. This emphasis is perhaps the distinguishing characteristic of the psychoanalytic approach. Even analysts who have undertaken more or less systematic observations of infant behavior have, as the distinctively psychoanalytic aspect of their contribution, made inferences about what goes on inside the infant-his perceptions, affects, and wishes, as well as the inner dynamic distribution of his energy. Traditional psychoanalytic methods are inapplicable, for the infant's experience is inaccessible even to indirect study through verbal report on the retrospective basis of recall. Nevertheless, the significance for psychoanalysis of an accurate basis for inference about infantile experience is not to be gainsaid.

It is easy for the behaviorist to criticize a focus on inner processes which are so inaccessible to observation. Let it be said, however, in defense of the psychoanalytic approach to the problem, that the behavioral phenomena at issue cannot be comprehended adequately without recourse to concepts of inner structures and processes which are not in themselves observable directly. For example, a concept of some kind of "inner representation" of an "object" is required, since there is overwhelming empirical evidence, in regard to both human and nonhuman species, that attachments or ties may persist throughout long periods during which the object is absent from perception and can provide 
no "reinforcement." Highly relevant to this issue is Piaget's ([1937] 1954) account of the development of the concept of the object and its permanency-a fact which has been acknowledged by a number of investigators of the infant-mother tie including Bowlby (1958), D6carie (1965), Escalona (1953), and Wolff (1960), who have been working within a psychoanalytic framework, and also Ainsworth (1967), Bell (1968), and Schaffer and Emerson (1964) among others.

Despite the fact that one cannot observe directly an "inner representation," there seems to be no substitute for behavioral studies in the case of a nonverbal (or preverbal) organism. Indeed, psychoanalysts have increasingly looked to behavioral studies of infancy to yield a more solid basis for such inferences than can be found through extrapolations from the fantasies and associations of older patients, whether adults or children. Psychoanalytically oriented behavioral studies include, for example, those by Brody (1956), Escalona, Leitch, et al. (1952), Mahler (1965), Mahler and La Perriere (1965 ), and Sander (1962, 1964) in addition to those mentioned above. Among the classical theorists, Spitz himself was a pioneer in behavioral studies.

Despite his empirical efforts, Spitz (e.g., 1965a) emerged with an account of the development of early object relations that differs in no essential respects from the accounts given by those who offered theoretical reconstructions of development in this period. His account of the neonatal period, for example, presents all items of sensorimotor equipment in an oral context; and, in general, the behavioral indices which mark progression from one stage of development to another are brought into harmony with his view that object relations develop out of need-gratification. As Bowlby commented:

A discrepancy between formulations springing direct from empirical observations and those made in the course of abstract discussions seems almost to be the rule in the case of analysts with first-hand experience of infancy-for example, Melanie Klein, Margaret Ribble, Therese Benedek and Rene Spitz. In each case they have observed non-oral social interaction between mother and infant, and, in describing it, have used terms suggesting a primary social bond. When they come to theorizing about it, however, each seems to feel a compulsion to give primacy to needs for food and warmth and to suppose that social interaction develops only secondarily and as a result of instrumental learning [1958, pp. 4-5].

In the absence of full dedication to behavioral observation, the empirical studies reported in the psychoanalytic literature have provided a meager yield of behavioral indices of significant steps in the development of interpersonal relations in infancy. This was highlighted when D6carie (1965) searched the literature for behavioral reference points in terms of which she could construct a scale to measure the development of object relations.

It must by now have become evident to the reader that I am critical of views which hold that interpersonal relations in general and the infant-mother tie in particular are secondary to orality or to primary drive gratification. Although it is impossible to review all the research evidence here, two crucial contributions must be mentioned. First, the whole body of evidence on "imprinting" (see reviews by Bateson 1966 and Sluckin 1965) shows that 
strong infant-mother ties may be formed very early through mechanisms bearing no relation to primary physiological drives and in the absence of any conventional rewards-not only in the case of precocial birds which were first observed by Lorenz ([1935] 1957) to display "imprinting" but in the case of mammalian species as well. Second, Harlow's experimental work with rhesus monkeys (e.g., 1961; Harlow \& Zimmermann 1959) makes it clear that feeding gratification is not the primary basis for infant-mother attachment in this species, and comparable evidence is accumulating for other mammalian species, including the human. Thus, for example, Ainsworth (1963, 1967) and Schaffer and Emerson (1964) reported attachments formed by young infants to familiar persons who play no part in the infants' routine care, including feeding. That oral components of experience are conspicuous in the infant seems obvious, as does the fact that the feeding relation is an important aspect of mammalian mother-infant relationships (cf. Ainsworth \& Bell, in press); but that these are crucial in the formation of the infant-mother tie is now clearly questionable.

Perhaps because of their preoccupation with orality and with the concept of primary narcissism, psychoanalytic writers have perceived the infant as passive in relation to his environment rather than in active interaction with it. (Exceptions have included Alice Balint, Escalona, and, more recently, Sander.) Consequently, they have viewed learning as passive, associative learning. Piaget's ([1936] 1952) account of development, in contrast, relies upon the active processes of assimilation and accommodation the developmental modifications of structures already present come about through active organism-environment interactions. Furthermore, the typical ethological description of infant-mother interaction emphasizes the important role of infant behaviors both in eliciting maternal responses and in active proximity seeking. It does not seem reasonable to assume that the human infant is passive while other infant mammals are active-and indeed direct observation of human infants convinced me (Ainsworth 1963) that they are very much more active and much less passively recipient than theoretical accounts have portrayed them.

Psychoanalytic accounts of development have tended to be normative, despite a basic therapeutic concern with individual deviations in development. Individual differences are at least in theoretical accounts-referred to differences in constitution, although clinical case studies are replete with implications of the potent influence of environmental influences. Escalona (1953) is one of the few exceptions. Although acknowledging constitutional bases for individual differences (Bergman \& Escalona 1949), she emphasized individual differences in experience as factors influencing the development of object relations. Referring to babies who choke or gasp during feeding, or who are pinched to arouse them from drowsiness, she comments: "The end result of having been fed is by no means always blissful oblivion." She concludes that "even before the baby can dimly recognize the difference between self and non-self . . . the range and quality of his experience may vary in many different ways." She suggests further that how the mother manages the baby should play a large role in helping or hindering his ego development-as well as the development of interpersonal relations. In contrast with most of the psychoanalytic approaches, those of the social learning theorists, which will be considered next, have tended to put entire emphasis upon environmental influence. It seems likely that it will be 
only through a thoroughgoing interactional approach-one which consistently acknowledges the contribution of both a structured organism and the environment in interaction with each other-that the development of individual differences can be comprehended.

A great strength of the psychoanalytic approach to early interpersonal relations is its emphasis on the interlocking between cognitive and social development. In no other theoretical approach is this point made so strongly. To attempt to segregate cognitive from other processes is even more artificial in regard to infancy than to later years. As Bowlby (1958), D6carie (1965), Escalona (1953), and Wolff (1960) have suggested, there is congruency between a psychoanalytic approach to the development of object relations and a Piagetian approach. It seems that a convergence of studies of the infant-mother tie and studies of sensorimotor development does indeed hold great promise.

Finally, regardless of the theoretical approach to the origins and development of early infant-mother relationships, the empirical key lies in intensive studies of mother-infant interaction over at least short spans of time. It is trite to observe that psychoanalytic theorizing about infancy has been handicapped by a lack of systematic empirical research. But, as will be seen, this fault is shared by most social learning theorists.

\section{SOCIAL LEARNING THEORIES OF DEPENDENCY AND ATTACHMENT}

Social learning theorists have, for the most part, been concerned with dependency rather than with attachment, although recently some have shifted their interest from the generalized relationship implied in "dependency" to the specific relationship implied by "attachment." In either case it is assumed that the formation of the infant-mother tie can be accounted for by the same "general laws of behavior" that comprehend all instances of learning-"laws" that vary somewhat from one theory to another.

Social learning theorists fall roughly into two groups in regard to their views of dependency. The first group, like the ego psychologists, views dependency as an acquired or secondary drive. The second group presents "dependency" as a mere label to be applied to certain kinds of learned behavior. As good reviews of the literature have been prepared by Hartup (1963), Maccoby and Masters (in press), and Walters and Parke (1964), this present review will confine itself to the most salient issues and will omit many details.

\section{Dependency as Acquired Drive}

Those who view dependency as an acquired drive conceive of the infant's tie to his mother as originating in the fact that he is helplessly dependent on her for the gratification of his basic physiological needs-for the reduction of his primary drives. The crying and other behaviors characteristic of the baby when he is in a primary drive state are reinforced through his mother's nurturant actions-that is, strengthened and made more likely to occur again. Meanwhile, the stimuli provided by the mother's face and presence become signals of gratification to come, and in this way the infant acquires a drive to be close to his mother and to seek her attention. This drive has been termed a "dependency drive." In the 
course of learning new behaviors are added to the cluster of dependency behaviors through which the drive is expressed. It is generally agreed that the behavioral expressions of a dependency drive come to include not only seeking physical contact and proximity but also seeking attention, help, and approval. Furthermore, through learning, the dependency drive becomes generalized so that it is no longer directed solely toward the mother as the source of reinforcement but also toward other people, including father, teachers, other adults, siblings, and other children.

This view of the origin of dependency stemmed chiefly from Hullian behavior theory. Its first exponents included Dollard and Miller (1950), Sears and his associates (1953, 1957, 1963, 1965), and Beller (1955, 1957, 1959). This view has also been much influenced by Freudian theory. Dollard and Miller (1950) explicitly stated their intention to translate psychoanalytic theory into Hullian terms. Their hope was that psychoanalytic constructs, based as they are upon inner experience and dynamics, could be translated into a set of theoretical constructs more relevant to observable behavior, which then could be subjected to empirical test more easily than the constructs which served as their original model. Derived as it was from the Freudian position, their view of the infantile origins of dependency, emphasized feeding, hunger, and orality, although other primary physiological drives were not altogether omitted from consideration.

In the first year of its life the human infant has the cues from its mother associated with the primary reward of feeding on more than 2,000 occasions. Meanwhile the mother and other people are ministering to many other needs. In general there is a correlation between the absence of people and the prolongation of suffering from hunger, cold, pain, and other drives; the appearance of a person is associated with a reinforcing reduction in the drive. Therefore the proper conditions are present for the infant to learn to attach strong reinforcement value to a variety of cues from the nearness of the mother and other adults .... . [It] seems reasonable to advance the hypothesis that the . human motives of sociability, dependence, need to receive and show affection, and desire for approval from others are learned [Dollard \& Miller, 1950, pp. 91-92].

Dollard and Miller resembled the Freudians in believing that derivative or secondary drives remain forever linked to their original primary drive roots. "These learned drives are acquired on the basis of primary drives, represent elaborations of them, and serve as a facade behind which the functions of the underlying innate drives are hidden" (p. 31) . Others leaned rather to the principle of functional autonomy (Allport 1937). Thus, for example, Sears, Maccoby, and Levin (1957) say: "In the long run, a child seems to develop a 'need' for these surrounding things [the circumstances surrounding the food-the mother's talking, hugging, smiling, and so on] that is quite separate from his 'need' for food. They become 'rewards' for him, loved and desired objects or situations which he will strive to attain" (pp. 14-15). Although at first the baby merely seeks gratification and the mother is the gratifying agent, later he seeks the mother as an end in herself.

The social learning theorists do not give more than casual attention to a catalog of the primary drives upon which the secondary dependency drive depends. They mention 
hunger, thirst, pain, discomfort, cold, and wet. Some of them imply that there is a primary need for physical contact; others assume that this too is an acquired drive. Perhaps the reason for the casualness is that all of these drives, whether primary or secondary, are gratified in the course of the mother's care. The mother's nurturance is a necessary condition for the acquisition of dependency. According to Sears, Rau, and Alpert (1965), the concept of dependency is equivalent to and derived from Murray's (1938) need for succorance 'the need for or dependence upon a nurturing object that must be always at hand or within call." The link between dependency and nurturance recurs throughout the dependency literature, and the most important aspect of nurturance is usually specified as the provision of food.

Beller (1955) provided a very explicit account of how the dependency drive develops:

The parent and his behavior constitute a complex stimulus situation for the infant. Certain aspects of this situation may be assumed to occur regularly and repeatedly when the child experiences drive reduction, and therefore will acquire reward value by association. For instance, the infant experiences physical contact with the parent while it also experiences reduction of its hunger drive through food intake. Thus physical contact with the parent, and later with people generally, acquires properties similar to those of food. just as in the case of food and hunger drive, the child will eventually manifest various kinds of behavior which will be terminated by mere physical contact with the parent. Conversely, when such behavior fails to lead to physical contact, frustration will set in. When this occurs the child may be said to have developed a secondary drive for physical contact. Second as the child's sensory apparatus develops and he no longer needs to be held during feeding, proximity to the parent acquirs properties similar to those for physical contact [p. 25].

Beller continued to describe how, in like manner, the child comes to acquire secondary drives for attention, help, and recognition (i.e., praise and approval). These five secondary drives, Beller hypothesized, are related together as components of a general dependence drive.

Several authors have suggested that simple, consistent, positive reinforcement does not adequately account for the acquisition of dependency. Influenced by Whiting's (1944) analysis of help seeking as a reaction to frustration, Sears, Whiting, Nowlis, and Sears (1953) hypothesized that the child's "early instrumental action systems" become transformed into a drive system by a process which "appears to result from the development of conflict between expectancy of reward and expectancy of non-reward or punishment. Only those actions which are followed by both reward and punishment become part of a secondary motivational system. The conflict between these two incompatible expectancies provides the drive strength for instigating the originally reinforced action" (p. 180). Sears later (Sears 1963; Sears et al. 1965) offered the simpler formulation that dependency does not come about so much through consistent reinforcement as through schedules of intermittent reinforcement. Bandura and Walters (1963) suggested that mildly rejecting parents, who usually reward dependency behavior, but who sometimes punish it or fail to reward it offer an intermittent reinforcement schedule which should strengthen the behavior. 
Beller (1959) stressed the role of anxiety in strengthening dependency. "Once dependency motivation has developed, the parent's attention and presence become synonymous with obtaining relief (from painful stimulation). Subsequently, a threat of losing the attention and presence of a parental figure becomes synonymous with being in danger of not getting relief from pain. Thus, a fear or anxiety mechanism that becomes an integral part of dependency is set in motion."

Stendler (1954), while acknowledging that an unusually strong dependency drive (overdependence) may result, as Levy (1943) suggested, from an overprotective mother who rewards dependent behavior and discourages independence, hypothesized that it may also come about through unusual stress occurring during a critical period toward the end of the first year, after the child already has acquired a dependency drive-stress which causes the child to "turn more and more and more to his mother and establish habits of overdependence."

If dependency is a generalized drive, as hypothesized-and certainly if it results in a generalized personality trait which differs in strength between individuals-high positive correlations should be found between measures of the various behaviors through which various components of the drive express themselves. It became apparent fairly early in research guided by the dependency-as-drive hypothesis that the obtained correlations were not as high as the hypothesis would require. In particular, help-seeking behavior emerged with low correlations with other dependency behaviors. This led some authors to distinguish between instrumental dependency behavior (help seeking) and "emotional" dependency (Heathers 1955) or "affectional" dependency (Kagan \& Moss 1962). Heathers pointed out that long before the infant wants his mother as an end in herself (emotional dependency) he has acquired instrumental responses for eliciting her help and nurturance; therefore help-seeking behavior should be excluded from the cluster of behaviors indicating emotional dependency. Heathers also distinguished between passive dependency (clinging and affection seeking) and active dependency (attention and approval seeking) and hypothesized that the passive form is more immature than the active form. (It is not clear on what basis Heathers considered clinging-which can be very active indeed-as more passive than attention seeking; furthermore, there is no evidence that clinging occurs earlier than attention seeking such as shouting for attention.)

As pointed out in the introduction to this paper, linguistic logic suggests that dependence and independence are at opposite poles of the same dimension. Waiters (Bandura \& Waiters 1963) differentiated between task-oriented and person-oriented dependent behavior, and later ( Waiters \& Parke 1964 ) pointed out that "many responses instrumental in obtaining social reinforcement or gaining approval could readily be classified as 'oriented toward achievement' Yet achievement-oriented behavior has been frequently utilized as an index of independence, a construct that has been traditionally structured as the obverse of dependency." Beller (1955) maintained that dependence and independence, although negatively correlated, were not at opposite poles of the same dimension; Heathers (1955) pointed out that dependence and independence are learned concurrently. In short, it was recognized by some learning theorists that it is not reasonable to assume that help 
seeking and approval seeking (and attention seeking) ought to reflect the same intraorganismic underpinnings as do proximity seeking and contact seeking. Furthermore, it is by no means clear that any of these behaviors can be considered antithetical to independence.

All authors agree in their assumption, however, that dependency as a drive, need, or trait is first acquired in relation to the mother, and generalizes later to other figures. At nursery school age-the age at which most research into dependency has been undertaken - it was assumed that the dependency shown by the child toward his teachers was essentially the same that he concurrently manifested toward his parents at home. Sears et al. (1953 ) assumed also that dependency manifested toward other children was the same as that directed toward adults, but Heathers (1955) and Beller (1955) did not.

If dependency is a drive, it ought to be strengthened under conditions of deprivation and weakened under conditions of satiation; it ought to operate in the same way as other physiological drives like the hunger drive. Gewirtz was the first to propose this test for the dependency-as-drive hypothesis; children who are reinforced by a social reinforcer such as verbal approval should learn more readily after a period of deprivation of social interaction and less readily if recently given much attention. His 1948 dissertation did, in fact, show that brief social isolation enhanced the subsequent effectiveness of social reinforcement, and his findings were replicated and extended by further studies both by himself and by others. Other experiments, such as those conducted by Waiters and his colleagues ( Waiters \& Parke 1964; Waiters \& Ray 1960), have suggested that susceptibility to social reinforcement may be heightened by anxiety or arousal and that stress manipulations tend to have the same effect as (brief) social deprivation or isolation. (I have inserted the qualification "brief" because it is by no means clear that "deprivation" and "isolation" for the brief periods introduced in these learning experiments can be assumed to have the same effects as the more extended experiences of longinstitutionalization in human infants or of long-term total or partial isolation in laboratory monkeys.) Despite these experimental findings that the effectiveness of social reinforcers may be changed by contextual circumstances, it is not necessary to conclude that there is a "drive" underlying dependency behavior. Gewirtz himself (1969), having reviewed his several experiments on social satiation and deprivation, suggested that it is gratuitous to introduce the concept of "social drive."

Discussion.-The issues raised by the dependency-as-drive theorists differ substantially from those raised by those who view dependency as behavior, and therefore they will be discussed separately. Many of the criticisms of the dependency-drive concept have, indeed, been raised by social learning theorists themselves.

The drive model has lost much ground in recent years among social learning theorists. Impressed not only with research into "imprinting" and into attachment in nonhuman primates, but also with studies of exploratory behavior, curiosity, and arousal, many learning theorists have rejected the secondary drive position as misleading and unhelpful.

Gewirtz (1961) criticized the secondary drive implication that the infant is passive and 
unresponsive when his biological needs have been fulfilled. He asserted that an organism may be in active interaction with its environment when not in a state of need and that "there may be potent reinforcing stimuli which do not seem at all relevant to organic needs." Gewirtz's contention was that behaviors which are generally attributed to "drive" can be accounted for completely in terms of the control of the conditioned reinforcing stimuli operating in the situation.

Waiters, although initially aligned with the dependency-as-drive position (Bandura \& Waiters 1963), soon criticized it for emphasizing states of deprivation or distress specially hunger, thirst, and pain-as primary sources of drive. Waiters and Parke (1964 ) referred to White's $(1959,1963)$ concept of competence and considered as important reinforcers the mother's behaviors which support the infant's acquisition of feelings of efficacy. They also emphasized the significance of emotional arousal. Any condition-not merely frustration and threat-which increases emotional arousal increases activity, alters perceptual thresholds, increases intensity of responses, and changes the internal cues to which a response will be made. And any state of heightened arousal facilitates orienting to and attending to other persons, and hence facilitates the formation of social behavior.

Walters and Parke (1965) moved steadily away from the secondary drive position toward an alignment with Bowlby's approach. While acknowledging need reduction and physical contact as significant influences, they emphasized that it is "stimulation in general" that develops social responsiveness. Their review directed attention to the smiling response, the distress cry, early visual capacities, exploratory behavior, play, and imitation, and pointed out that these are largely mediated through the distance receptors and have little or no obvious link to the nurturant situation which other theories have emphasized as the basis of dependency. Finally, they declared themselves in favor of Bowlby's concept of attachment in preference to the concept of dependency-which, they said, will "probably prove to be of little ultimate value in conceptualizing social phenomena."

Sears, who was a chief proponent of the view of dependency as acquired drive, and who based much of his extensive research on this theoretical foundation, later acknowledged doubt of the usefulness of the drive construct:

Presumably, this view has been taken because of the spontaneous character, and persistence, of young children's seeking for attention affection and reassurance from their parents, the seeming increase in strength of such supplication when nurturance or affection is withheld, and the reduction of such striving when a substantial amount of nurturance has been given. If we acknowledge, as we must, that there is no critical evidence to support the drive conception, then we must ask what alternative explanations can be used to account for these phenomena [Sears 1963, p. 28].

He noted that one possible alternative is Gewirtz's (1961) operant conditioning model, which will be considered in the next section.

Another alternative to the concept of secondary drive would be to propose that dependency (or attachment) might be a basic drive in its own right, but the current climate of opinion 
opposes expanding the catalog of basic drives beyond those that are tied into fundamental, physiological, homeostatic systems. To limit the drive concept to such systems does not imply that dependency behavior-or attachment behavior, or exploratory behavior, for that matter-is unmotivated. Motivation does not necessarily imply something extrinsic to the behavioral system which has been activated. The consensus now seems to be that motivation may be intrinsic to the behavioral system itself. As research becomes directed toward an ever more detailed examination of behavioral systems and how they operate, it becomes less and less useful to think of broad general drives as comprehending several component behavioral systems (see, e.g., Hinde 1966).

The studies of the effects of "isolation," arousal, anxiety, stress, and intermittent reinforcement schedules upon dependency behavior and upon the effect of social reinforcers demonstrate that these conditions have an intensifying or heightening influence. Nevertheless, the fact that these various conditions heighten the intensity of the behavior in question does not necessarily mean that the interpersonal relationship has thereby become stronger. This heightened intensity of behavior does not mean that the child thereby has acquired a stronger dependency relationship in any lasting sense either with his mother, or with a strange experimenter whom he has never met before and will probably never meet again. The relationship may be affected by these intensifying factors, but the change may well be qualitative rather than quantitative-it may have become more anxious.

Earlier, the question of the correlations between dependency behaviors was touched upon. If dependency is either a generalized drive or a generalized trait, these correlations should be positive and high. Seeking contact, proximity, attention, help, and approval should not prove to be so highly specific either to their object or to the situation that the intercorrelations are low. Hartup (1963), reviewing the literature, concluded that it is doubtful that dependency is a unitary concept rather than a label for a multiplicity of factors. Walters and Parke (1964) were similarly skeptical about dependency as a unitary dimension. "Strictly speaking, aggression, dependency and other socially significant behavior patterns are not variables in the sense in which the term 'variable' is used in the natural sciences, and it is perhaps time that social scientists ceased pretending that they are."

While considering contact seeking and proximity seeking the crucial behavioral manifestations of attachment, I would emphasize that these behaviors have a primary basis, that the intensity of these manifestations is highly dependent upon the situation, and that their relation to approval seeking and other behaviors traditionally considered as manifestations of dependency must be the subject of developmental research and not merely cross-sectional correlations.

At this juncture it is appropriate to point out that none of the research based on the secondary drive model has involved direct observations of the development of child-mother relationships during the first 2 years of life. Stendler (1954) ventured a hypothetical description of such development on the basis of milestones identified by Gesell and Ilg (1943). Her account and those of others previously reported consist of reconstructions of infant behavior which are tied even less closely to direct observations 
than the reconstructions of infant experience made by psychoanalysts. The direct observations of these social learning theorists have been made of children of nursery school age or older, chiefly in interaction with teachers and peers rather than with parents; and, with the exception of the Fels study (Kagan \& Moss 1962), they have considered development cross-sectionally rather than longitudinally-if indeed they have studied development of dependency at all.

\section{Dependency as Behavior}

The present consensus among social learning theorists is that "dependency" is merely a convenient label for certain kinds of learned behavior. This view is concerned neither with dependency as a generalized drive nor with dependency as a generalized trait. The shift in position parallels the gradual shift of emphasis in learning theory from the Hullian model to the Skinnerian operant conditioning model. This view considers that all social behavior follows "the general laws of behavior" and that one must proceed by examining the environmental stimuli which control behavior. As Gewirtz (1961) said of the laws of operant conditioning: "These concepts can order the case under which (the components of) unconditioned responses of the child which occur (either reflex or 'voluntary') are differentiated out and shaped (i.e. conditioned) by some of their immediate environmental consequences, which function as reinforcing stimuli."

The key concept for the instrumental conditioning group is the reinforcing stimulus-which is "any stimulus event which follows a response and affects certain of its aspects, e.g. its rate of emission, amplitude, or latency" (Gewirtz 1956). Positive reinforcers strengthen responses when they occur; negative reinforcers strengthen responses when they are removed. According to Bijou and Baer: "The essential function of the mother is to provide positive reinforcers to the infant and to remove negative ones .... In doing these things ... the mother herself, will, as a stimulus object, become discriminative . . . for the two reinforcement procedures which strengthen operant behavior. Thereby, she acquires positive reinforcing function, and lays the foundation for the further social development of her infant" (1965, pp. 123-124).

Bijou and Baer offered a list of primary reinforcers, many of which are obviously related to basic physiological drives. In addition, they suggest that the mother provides tactual stimulation, stimulus change, and help to the infant in controlling his environment. None of these reinforcers is offered as more "primary" or more important than any other as a basis for the acquisition of dependency behavior. Dependency is still linked to the nurturant mother, to be sure, but nurturance is defined broadly and not narrowed either to food giving or to tension reduction.

Gewirtz (1969) held that it "remains an empirical question which of the myriad potential stimuli in the human infant's milieu emerge at each growth point to function as unconditioned ('primary') positive reinforcers for his behaviors to effect learning." He continued: "A very large variety of events can function as positive reinforcers in early human life, in addition to those which are thought to meet the infant's organismic needs as narrowly conceived." Nevertheless the infant receives many of the stimuli which are 
reinforcing through his relations with his caretaker. Whichever stimuli caretakers provide consistently preceding or concomitant with "functional reinforcement" to the infant are those which should function subsequently as social reinforcers for him. He was cautious about implying that physical contact could be a primary reinforcer. He suggested that "contact holding" may have acquired part of its reinforcing power through association with potent reinforcing stimuli concomitant with being held-such as feeding, relief from pain, "interesting" environmental changes, and other caretaking.

Bijou and Baer (1965) pointed out that the mother's important stimuli for the baby, which allow her to be discriminated from the rest of the environment and the people in it, are mediated chiefly through distance receptors, although some are tactual.

In effect, the mother is a changing sample of stimuli some of which are unique to her, but many of which are shared by other people. Thus stimuli from a mother which become discriminative for the reinforcement may overlap with stimuli from other people, and the baby's behaviors which have become strengthened to mothers stimulation may be evoked by others who present the same or similar stimuli. Consequently there are natural bases for both discrimination of the mother from all other people and for generalization from the mother to others [Bijou \& Baer 1965, p. 132].

Nevertheless, mother at a distance is scarcely discriminative for reinforcement at first; most of the reinforcement operations the mother performs are undertaken while she is in close physical relationship with the baby. Therefore, stimuli marking differences in distance will themselves become functional, and closeness to the mother takes on reinforcing power. Behaviors of the baby which produce proximity will be strengthened, and behaviors losing proximity will be weakened. This is the basis for the establishing of responses such as crying and following as mediating attachment. They are "discriminated operants maintained by the proximity functioning as a positive reinforcer."

Gewirtz (1969) used similar concepts to account for both dependency and attachment, holding that they are "best conceptualized as abstractions for classes of functional relationships involving the positive stimulus control over a wide variety of an individual's responses by stimuli provided either by a class of persons (dependence) or by a particular person (attachment)." Further: "Attachment is seen as a form of dependence of the behavior systems of one person upon the unique physical and behavioral stimuli provided by a particular other person (or a very few individuals)." Both dependency and attachment are acquired by a conditioning of various behavior systems-such as approach, orientation, regarding, following, remaining near, touching, smiling, and vocalizing-with respect to a specific person or to a class of persons. The physical and behavioral characteristics become discriminative and reinforcing stimuli that maintain and indeed control the child's behaviors. The greater the number of behavior systems of the child under the stimulus control of a particular person relative to the number of behaviors under the stimulus control of others, the greater the degree of control over each behavior system; and the greater the number of stimulus settings in which the control operates, the stronger the attachment may be said to be. 
Gewirtz (1969), perhaps more than any other in the instrumental conditioning tradition, has interested himself in integrating his system with the views of those specially Bowlby and myself-who have been influenced by ethological concepts. He acknowledged that there may be genetically determined biases and "species-specific" behaviors in the human, but considered as open issues whether any of the responses implicated in the acquisition of attachment are species-specific and what unconditioned stimuli might act as releasers for them. He seems to draw a sharp distinction between learned behavior and behavior which is "unlearned," "innate," or "hereditarily-determined," suggesting that if learning can be implicated behaviors cannot be labeled as species-characteristic. Thus he suggested that the human face probably has no prepotent "releasing" value for smiling behavior, as a number of studies have suggested, but rather that through conditioning it becomes a discriminative stimulus for the child's smiling. Nevertheless, in another context he granted the possibility that genetic biases may facilitate the learning of some behaviors and inhibit the learning of others.

Gewirtz characterized Bowlby's and my approaches as "prelearning" approaches-compatible with learning considerations despite the fact that neither specifies the learning processes through which attachment is acquired. These "prelearning" approaches emphasize the species-specific behavior systems from which attachment behavior stems. Not only is this still an open issue but, Gewirtz implied, once learning takes over, any initial facilitation or inhibition of learning that might have been offered by genetic biases is totally overshadowed (indeed is probably lost) in the subsequent reinforcement history.

Gewirtz (1961, 1969) emphasized contingency as a condition for reinforcement, thus making very explicit what is implied in other social learning theories. For an environment to be functionally effective for learning and for control of behavior, it must provide stimuli which can be discriminated by the child and reinforcers which are contingent upon his behavior. The stimulus to be reinforcing must be an immediate consequence of his response. In other words, the child must be able to perceive the consequences of his behavior; his behavior must elicit feedback from his environment.

Gewirtz (1969) and also Bijou and Baer (1965) described mother-infant interaction as a chain of mutually reinforcing behaviors, in which the response of the mother contingent upon the response of the child tends to re-evoke the infant's behavior, which reinforces the mother's behavior, upon which it is contingent. Not only is the infant's behavior shaped by reinforcers from the mother, but the mother's behavior is shaped by reinforcers from the infant. The behavior of each comes under stimulus control of the other. Thus each mother-child pair will build up its own distinctive interaction chains and its own patterns of behaviors constituting attachment. Gewirtz suggested that behavior systems which appear to be "irreversible" could be extinguished if the conditions maintaining them were removed, but often enough the behavior of the environment is so "locked in" to the child's behavior that it serves to maintain it, even though the "maintaining contingencies" are not easy to identify.

Cairns (1966a) has advanced a theory of attachment behavior-and he used the term 
"attachment" rather than "dependency"-on a Guthrie-Estes contiguity learning model. The organism, regardless of age and species, becomes attached to an object, whether animate or inanimate, which is constantly present in the organism's environment, through a process of associative conditioning. Reinforcement is held not to be necessary for attachment to occur, although it might have a facilitating effect. The object of attachment gains control over the animal's behavior by virtue of being present as an accompaniment of many of its responses and thus becomes a cue for those responses. Different objects or events have different weights in any particular stimulus pattern-"a joint function of the sampling probability and the number of elements within the set [of stimulus elements]." Some objects are more salient than others, either because they have greater "attention-getting" characteristics or because they are more involved in the animal's on-going responses and thus acquire discriminanda and manipulanda properties. Thus highly conspicuous or response-involved events have greater weights.

Cairns (1966b) demonstrated that lambs could become attached to television sets if kept in isolation from other animals but in constant propinquity to a set in operation, just as Bateson (1964) demonstrated that chicks could become imprinted to a conspicuous static object under similar circumstances. Cairns (1966a) acknowledged that attachment is more common to animate than to inanimate objects because the former usually are more salient and more capable of becoming involved directly in the infant's responses. Under conditions of interaction, the behavior of each animal has many cues which control the behavior of the other. Cairns held that rewards do not affect attachment strength in any direct manner, but indirectly by increasing the salience of the rewarding object. Similarly, punishment may increase attachment strength by enhancing the salience of the object of attachment, or it may decrease it if the animal tends to withdraw from the noxious stimulus thus reducing its salience. In general, however, the heer number of interactions with the object of attachment determines the attachment strength, not the quality of the interactions or their outcomes.

Important in Cairns's theoretical model is the effect of separation from the object of attachment. Separation should have the effect of disrupting behavior because it removes the cues to which so many of the animals' response systems have been conditioned. Despite this initial disruption of behavior, separation should immediately bring in train a process of relearning, of attachment to the most salient object now in the environment, and of diminution of behavioral disruption. Cairns specifically states that the strength of attachment to a specific object should be inversely related to the length of separation from that object. He quotes experimental evidence to support this view.

Finally, Cairns considers the acquisition of new behavior patterns which he might have termed "attachment behavior" but did not. 1f the object of attachment-a "heavily weighted, generalized cue"-is removed, thus disrupting all established behavior patterns, any response occurring in the ensuing disjointed sequence of responses which reintroduces or regains the object of attachment will be conditioned to the separation situation and thus will be more likely to recur if the situation recurs.

Discussion.-Cairns rested much of his argument on evidence that disturbance occasioned by separation from the object of attachment diminishes as separation continues, and thus 
separation, according to his model, lowers attachment strength. That continuing separation diminishes disturbance is supported by research with both young children and nonhuman primates, and indeed there is support for Cairns's claim that the separated infant may, under favorable circumstances, form other attachments while separated from his mother. It seems to be a paradox, however, that once attachments are well established they can and usually are maintained over periods of separation, even over quite prolonged periods. Both human studies and some studies of nonhuman primates show that a pronounced heightening of attachment behavior takes place upon reunion with the mother after separation, either immediately, or (in the case of some humans) after some period of delay. The attachment has survived the period during which the infant's behaviors were not suppored by the absent object of attachment. Cairns acknowledged the possibility of this outcome when he said that those habits that the infant had acquired specifically with respect to the object of attachment presumably would remain relatively intact if the infant and the object were abruptly separated and kept apart. This acknowledgment seems, on the face of it, to be directly contradictory to his statement that the strength of attachment should be inversely related to the length of separation from the object. Presumably the former statement is applicable to the period of separation and the latter statement pertinent to the reemergence of attachment at the time of reunion. Cairns does not reconcile the seeming contradiction. In general, social learning theorists have not attempted to comprehend reunion behavior within the paradigms of conditioning and extinction.

Cairns, Gewirtz, Bijou, and Baer have rid themselves of the misleading ramifications of the concept of acquired drive and of a superstructure based on homeostatic drives or orality. The operant conditioning approaches go to an equally misleading extreme in minimizing, and indeed almost ignoring, the organismic determinants of behavior. (Cairns, while emphasizing associative learning, does not rule out the possible role of organismic determinants, including genetic determinants.) Gewirtz, Bijou, and Baer place entire emphasis on the environment and on the relative potencies of different stimulus events to increase the strength of any behavior which the organism may happen to emit. The only condition within the organism which is acknowledged as an important influence is whatever may be represented by its reinforcement history. The neurophysiological state of the organism tends to be neglected as one of the determiners of the activation of a behavioral system. The closest Gewirtz (1969) has come to acknowledgin such a determiner was in his discussion of "contextual-setting conditions"-which include figure-ground and masking effects, fatigue effects, cues, and deprivation and satiation effects.

In his attempt to bring his system into harmony with Bowlby's and my ethological approach, Gewirtz acknowledged that genetic biases may influence learning, but his sharp distinction between learned and "hereditarily determined" behavior is not drawn by contemporary geneticists or ethologists, who view development as taking place through continuous interaction of a structured organism and the environment. Thus Dobzhansky (1956) pointed out that "at any stage of development, the [phenotypic] outcome of the development depends on the genotype and on the succession of environments which the developing organism has encountered up to that stage." There is no behavior uninfluenced 
by the environment in which it develops. Hinde (1966) suggested that it is useful to conceive of a continuum of behaviors ranging from those which are environmentally stable and relatively little influenced by environmental variations to those which are relatively environmentally labile. Behavior previously designated as "unlearned" or "istinctive" may be placed toward the stable end of the continuum without any implication that learning is absent in the course of its development-just as there is no implication that behavior at the relatively labile end is uninfluenced by the genetic code.

The evolutionary approach implies that when a species has become adapted-genetically adapted-to an environment there is an interlocking between the developmental potentialities incorporated in the genetic code and the potential impingements of that environment. In some species more than in others, this adaptation allows for a safety factor of learning, which prevents limitation of the behavioral repertoire to fixed-action patterns. Gewirtz, however, suggested that behaviors which are very rapidly learned as "the result of the hereditarily-determined structure and growth of receptor and effector systems" cannot be "species-specific," nor can behaviors which may depend on experiences universal in the species. On the contrary, ethologists hold that those aspects of the genetic code which regulate the development of attachment of infant to mother are adapted to an environment in which it is a well-nigh universal experience that it is the mother (rather than some biologically inappropriate object) who will be present under conditions which facilitate the infant's becoming attached to her. This implies that the sensory equipment of the species may make its members more sensitive to certain classes of stimuli than to others, that the behavioral systems characteristic of the species may be more readily activated and terminated by some classes of environmental events than by others, and indeed that some modifications of these systems are more easily learnable than others. These are a few instances of "genetic biases."

The social learning theorists tend to have difficulty in incorporating into their systems any view of inner structure-whether genetic encoding, neurophysiological structure, or cognitive structure. As both Lewin (e.g., 1936) and Piaget (e.g. [1936] 1952) have implied in their interactionist theories, all developmental changes-including all learning-come about through a modification of the structure already present in the organism as a result of its interaction with the environment. This process applies not only to modification of the structure initially present-whether we are initially focusing on the zygote, the neonate, or the school-age child-but to all changes which come about through subsequent transactions with the environment. Development takes place through structural transformations. The earlier structures, although transformed, are never altogether lost. They are neither demolished nor replaced in the course of subsequent learning. The ethological and the psychoanalytic views share with Lewin and Piaget a respect for the persistent and enduring nature of structure despite the many transformations and elaborations to which it may be subjected. In contrast, the implication of both operant conditioning and contingency-learning theories is that behavior, whatever genetic biases may be acknowledged as starting points, is all toward the environmentally labile extreme. Response strengths may be increased through environmental contingencies, and they may also be extinguished. If difficult to extinguish, the implication is that the behavior in question is still supported by environmental contingencies and not that well-consolidated or deeply rooted structures tend to resist change. 
One great strength of operant conditioning theory is its insistence that to be reinforcing a stimulus must be contingent upon the behavior in question. This concept is somewhat similar to the concept of feedback, which has come to psychology as a central concept through control systems theory (e.g., the TOTE model of Miller, Galanter, \& Pribram 1960.) Despite their obvious similarities, "contingency of reinforcement" has passive implications in comparison with "feedback." Feedback covers the case in which the organism is actively testing out a behavior to see what the consequences may be; at the least it implies that the organism (or computer simulation thereof) is especially programmed to receive input relevant to the outcome of the test. Feedback which "matches" the inner template given, however crudely, by the genetic code is likely to facilitate the very beginnings of the development of attachment. Later, as the infant becomes more capable of active testing, feedback can potently influence the quality-and perhaps also the strength of his attachments. White's $(1959,1963)$ concepts of "efficacy" and "competence" are relevant here. When the infant, in testing out an action, achieves the consequence he is seeking, he has a "feeling of efficacy." An accumulation of feelings of efficacy forms the basis of his "sense of competence." It seems reasonable to suppose that the infant may accumulate a greater sense of competence with physical objects than with social objects, or vice versa, and that the quality of his attachments would be pervaded by feelings in the competence-incompetence dimension.

Both control systems theory and an evolutionary, ethological approach postulate a structured organism-structured from the very outset-and both postulate that all behavior, and indeed all development, comes about through the interaction of that structured organism with those aspects of the environment which its structure is sensitive to receive as "input." Some of the features of these approaches have already been considered in discussing social learning theories; let us now consider these approaches in combination and more systematically.

\section{AN ETHOLOGICAL APPROACH TO ATTACHMENT}

The past decade has been a period of ferment in developmental psychology. Two substantive areas have been foci of interest-cognitive development and the development of attachment-and in both the period of infancy has been the subject of unprecedented research activity. The chief common ground shared by diverse and lively new approaches is a renewed interest in what is inside the organism, in what is there at any given point of development which can be transformed in the course of organism-environment interaction. The cognitive psychologists have been concerned with the foundations and transformations of cognitive structures. Those interested in attachment have been concerned with behavioral systems, conceived as having an inner organization as well as outward manifestation and as having a context not only in terms of the environment but also in terms of the intra-organismic neurophysiological state.

Increased attention to inner structure and function has come about in large part through the impact of the biological sciences. There are a number of points of impact. First, and perhaps most obvious, is the influence of ethology, beginning with Lorenz ([1935] 1957) but continuing on a broad front as comparative psychology and ethology have become interwoven (cf. Hinde 1966). Second, there is a renewal of interest in evolutionary theory, attributable partly to ethology and exemplified in the current emphasis on studies of nonhuman primates, including 
field studies. An evolutionary emphasis has also been encouraged by the spectacular recent advances in molecular biology and genetics. Third, physiological psychology has done much to focus interest on what goes on inside the organism-on neurophysiological and endocrine processes which, in interaction with environmental stimuli, serve to activate or terminate the activity of behavioral systems. Finally, even cognitive psychology has been affected by biology-indirectly, through the significant influence of Piaget who was, himself, profoundly affected by his biological starting point.

Control systems theory and computer models have also directed attention to what is inside. Attention has turned from constructing models of human behavior on the basis of machines to constructing machines on the model of human cognition and behavior. All of this has resulted in increased interest upon what is inside the organism "to start with," how this inner programming affects the response to environmental input, and how it becomes transformed as a consequence of organism-environment transactions.

These several trends have converged to stimulate new approaches to a study of interpersonal relations; no one represents the effect of this convergence better than does John Bowlby. It is perhaps no accident that it is a psychoanalyst who has given leadership in formulating a new biological approach to interpersonal relations. One of Freud's greatest strengths was his view of the psychic superstructure as rooted firmly in the biological nature of man. In effect, what Bowlby has attempted is to update psychoanalytic theory in the light of recent advances in biology. He proposes to replace Freudian instinct theory with a set of propositions, testable through research, more closely in line with present-day knowledge, while at the same time respecting the many psychoanalytic contributions to understanding human experience and behavior which are not tied inextricably to an antiquated instinct model. The period of life most clamorous for theoretical revision is infancy and early childhood-the very period in which psychoanalysis has been most handicapped because this period is inaccessible to its own unique methods of investigation.

In presenting Bowlby's theoretical contribution it is difficult to distinguish what is especially his from what is attributable to others who have been caught up in the same impetus from converging trends. His 1958 paper on the nature of the child's tie to his mother inspired research and helped to conceptualize the findings of research originally undertaken outside the framework of attachment theory. Among those who have been influenced by Bowlby or by the same trends which have influenced Bowlby are-to name a few and to cite only one publication each -Ainsworth (1967), Ambrose (1963), Caldwell (1962), Freedman (1967), Morgan and Ricciuti (1968), Rheingold (1963), Robson (1967), Schaffer and Emerson (1964), Scott (1963), and Walters and Parke (1965). Although Bowlby has been influenced by ethologists and comparative psychologists, they have also been influenced by him: for example,

Harlow (1963), Kaufman and Rosenblum (1967), and Spencer-Booth and Hinde (1966). Bowlby's most recent theoretical formulation (1969) can be viewed as both cause and effect. Much of it is an outgrowth of earlier publications (e.g., 1957, 1958) more fully formulated. But much of it is based upon and reviews the research of others. 
The basic thesis, as enunciated in 1958; is that an infant's attachment to his mother originates in a number of species-characteristic behavior systems, relatively independent of each other at first, which emerge at different times, become organized toward the mother as the chief object, and serve to bind child to mother and mother to child. Originally, he described five such behavioral systems as contributing to attachment: sucking, clinging, following, crying, and smiling. In the course of development, these become integrated and focused on the mother and thus form the basis of what he termed "attachment behavior." In his new (1969) formulation Bowlby still holds these as important, but having come to a "recognition of the very sophisticated forms that behavioral systems controlling instinctive behavior may take," be introduces a control systems model and postulates that between the ages of about 9 and 18 months the simpler behavioral systems become incorporated into "far more sophisticated goal-corrected systems . . . so organized and activated that a child tends to be maintained in proximity to his mother." Whereas in 1958 he described his as a theory of component instinctual responses, in 1969 he describes the new formulation as a control theory of attachment behavior.

\section{Theoretical Background}

The keynote of Bowlby's position is that attachment behavior has biological underpinnings which can be comprehended only within an evolutionary context. He acknowledges that the human species is one in which there is a large proportion of environmentally labile behavior which enables it to cope with a wide range of environmental variations. Further, in comparison with other species, there are fewer stable fixed-action patterns, more plasticity for learning, and a longer period of infantile helplessness. Nevertheless, for the human species to have survived despite extreme, extended infantile vulnerability, he finds it reasonable to suppose that its young must be endowed with some relatively stable behavioral systems which, through sustaining parental care, serve to reduce risk through the long period of immaturity. Indeed, attachment behavior in the young, together with the reciprocal parental care behavior, tend to be among the most environmentally stable behavioral systems across species.

The child's attachment behavior has the "predictable outcome' of bringing him and his mother into closer proximity, whether through signals which attract his mother to him or through his own activity. Although absence of contact-or distance between child and mother is one of the conditions which may activate a system of attachment behavior, the stimulus situation in the environment is but one of a complex of interacting factors implicated in activation. Others include the hormonal state of the organism and central nervous system activation. Once attachment is activated it does not in all child-mother pairs or at all times have the inevitable outcome of increasing proximity or maintaining contact, but it has this outcome often enough in enough pairs to make it "predictable"-usual or probable.

The predictable outcome of a behavioral system is not the same as its "biological function." The function of a system is the one that gave it species-survival advantage in the "environment of evolutionary adaptedness"-the original environment in which the species first emerged. The biological function of the behavior may or may not give special advantage in one or another of the various environments in which present-day man lives, but this is a quite distinct 
consideration. Genetic programming continues to bias the infant to behave in ways adapted to the original environment of evolutionary adaptedness, and, similarly, under all the layers of individual learning and cultural acquisition, there is still a bias for mothers to behave reciprocally-a bias which may have been more or less sharpened or blunted by learning in any individual mother.

Available evidence suggests that when man first emerged as a distinct species he sustained himself by hunting and gathering in a savannah environment. If we wish to understand what kinds of reciprocal patterns of infant and parental behavior could give survival advantage in that environment of adaptedness, we may gain clues from a study of primitive hunting and gathering societies, and those ground-living monkeys and apes who occupy an environmental niche presumably not very different from that in which the earliest humans lived. It is within the context of a review of this body of anthropological and ethological literature that Bowlby proposes that the biological function of attachment behavior, and of the reciprocal maternal behavior which he terms "retrieving" behavior, is to protect the infant from danger, and specifically from the danger of attack by predators.

Although in the environment of evolutionary adaptedness the maintenance of contact between mother and infant has the predictable outcome that the infant also gains nutrition, it is a cornerstone of Bowlby's position that feeding gratification does not form the essential basis for attachment of infant to mother-and he cites evidence to which reference has already been made in earlier sections of this review.

Bowlby characterizes attachment behavior as instinctive, but points out: "Instinctive behavior is not inherited: what is inherited is a potential to develop . . . behavioral systems, both the nature and the forms of which differ in some measure according to the particular environment in which development takes place." Even in species much less labile than man, there is a margin of flexibility provided by learning-for example, !n learning the object to which attachment behaviors are to be directed. Learning also enters in with the augmentation (reinforcement) or lessening (habituation) of specific attachment behaviors as a result of feedback received from the environment. If the environment deviates too widely from the original environment of evolutionary adaptedness, developmental anomalies may occur, but, in an environment similar to that to which the behavioral systems were originally adapted, the infant's learning modifies behavior in a direction promoting fulfillment of its biological function.

Bowlby is not concerned solely, or even primarily, with the genetic biases which underlie the prototypical attachment behaviors through which the infant, in due course, becomes attached to his mother. His chief focus is on well-developed attachment behaviors and their reciprocal maternal behaviors in the interaction of, say, a 2-year-old child with his mother. These too are "instinctive" (in Bowlby's sense of the term), even though they may be at the same time described as "purposive" or "goal-directed." This brings us to the role of control systems theory in Bowlby's formulation.

A control system is a man-made device which simulates purposive behavior. The "goal" is built into the device by the men who "set" it, or give it its program. The essential feature of the machine, which enables it to achieve its goal, is feedback. There is a receptor system (input), 
and an effector system (output); the input feeds in to affect the output in accordance with the way the device is set or programmed. Bowlby gives as an example of a complex control system the anti-aircraft missile which seeks out its goal-an enemy aircraft-and despite evasive maneuvers on the part of its prey, intercepts it and destroys it. He compares the missile's performance to the stoop of the falcon in intercepting its prey, a behavior which is instinctive according to all contemporary criteria, despite the fact that it is goal-directed and complex. The genetic programming of the falcon-like the programming of the missile -ensures the sensorimotor and central equipment which enables it to guide its stoop in such a way that continuously changing visual input guides the movements that control the course and speed of flight so that the predictable outcome is the interception of prey. The control system model provides a basis for considering much complex, goal-directed behavior (Bowlby prefers the term "goal-corrected") in man as well as in the falcon as having an inbuilt bias in terms of species-characteristic genetic programming.

Behavioral systems can be coordinated into sequences not only as chains of fixed-action patterns-the stock-in trade of S-R theory-but also in hierarchical organizations. One form of hierarchical organization is one governed by a plan-and here Bowlby draws on Miller et al. (1960) . In a plan, the overall structure of the behavior is governed by a goal (Bowlby prefers the term "set-goal"), but the individual behavioral components are variable according to circumstances. To be sure, the infant throughout much of the first year of life has not developed the cognitive structures necessary for a plan; his behavior is organized along the simpler lines of fixed-action systems and chains thereof. But toward the end of the first year his behavior becomes increasingly "goal-corrected" and he can formulate simple plans; these later become increasingly facilitated by the symbolic and short-cutting aid of language. Although the plans of human adults seem to have left instinctive behavior far behind, the set-goals may still be those characteristic of the species, and some of the components entering into the plan-hierarchy may themselves be organized on a simpler basis. Basic to this view, as Pribram (1960) has asserted, is the notion that, through evolutionary history, the higher species transforms the equipment of its predecessors in the evolutionary chain, adding to it, but not completely discarding the old equipment. Similarly, in ontogenetic development, the earlier and simpler systems are not lost, although they may be overridden by new patterns to make up the organization of mature adult behavior. They may remain as integral components of the adult system, perhaps to come out only under special circumstances, as for example, a conflict situation.

What roles do affect and emotion, so emphasized in psychoanalytic theories, play in Bowlby's formulation? He fits these into his control systems theory as "appraising processes." Sensory input, whether relating to the state of the organism or to the state of the environment, must be interpreted and appraised in order to be useful. "Feelings"-a term which Bowlby uses to cover both affect and emotion-are important appraising processes, although not all appraising processes are felt (i.e., conscious). Appraisal is a complex process which includes comparing input to inner "set-points" or standards and selecting certain forms of behavior in preference to other forms in accordance with these comparisons. Many of the basic set-points for comparisons (such as species-characteristic preferences and aversions), and the simpler behaviors of approach and withdrawal which ensue, are environmentally stable. Others are clearly labile. Very frequently the interpreted and appraised input is experienced inherently in terms of value as pleasant or unpleasant, for example. But, whether felt or unfelt, the processes 
of appraising changing environments and changing organismic state play a vital role in the control of behavior. To the extent that behavior is organized as a plan, feelings provide an important monitoring service, focal in the processing of input which guides further behavior. Does being "feelingly aware" add anything to appraisal? Bowlby suggests that "keen feeling goes with alert attention, with refined perceptual discrimination, with . . . planning of behaviour, and the well-registered learning of results."

What has happened to "drive" in Bowlby's formulation? Bowlby is concerned with the conditions-both intra-organismic and environmental -that activate and terminate behavioral systems. Whether any particular behavioral system is operating as a fixed-action pattern or organized within the hierarchy of a plan, it adds nothing to our understanding to postulate a drive. Motivation is implicit in the behavioral system. It is not helpful to postulate a multiplicity of drives, one for each behavioral component; it is redundant to postulate a comprehensive drive to cover all behaviors which are regulated by a common "set-goal." Once the child's cognitive equipment enables him to organize his attachment behavior on a goal-corrected basis, he can be described as seeking proximity to his object of attachment. To postulate that he has a drive for attachment or for proximity would be superfluous and might well obscure the search for the conditions which activate and terminate attachment (proximity-seeking) behavior.

It is in the context of this theoretical background that Bowlby advances his view of attachment-a view that takes into account both (a) the intraspecies uniformities in attachment and its development and (b) the deviations which are nonadaptive and which form the basis for a variety of pathologies. It is with the former that we are concerned here.

\section{Attachment Behavior and Its Development}

Bowlby distinguishes four main phases in the development of attachment behavior: Phase 1, orientation and signals without discrimination of figure; Phase 2, orientation and signals directed toward one or more discriminated figures; Phase 3, maintenance of proximity to a discriminated figure by means of locomotion as well as by signals; Phase 4, formation of a reciprocal relationship. Whereas other theoretical orientations have focused on Phases 1 and 2, and on the transition between them, Bowlby's special contribution is in regard to Phases 3 and 4, especially the former. Indeed, he begins with a consideration of the behavior characteristic of Phase 3.

Much of the child's attachment behavior is mediated by behavioral systems which, once they are fully developed, have proximity to the mother as their set-goal. Any deviation from the distance specified by the set-goal, whether brought about through the action of the mother, of the child, or of someone else, is likely to activate the systems until the distance specified is restored. The behaviors mediating attachment are of three classes: orientational, signaling, and executive. To keep informed of the mother's whereabouts, the child orients to her, tracking her movements visually and aurally. To attract his mother to him, he can signal through crying, smiling, babbling or calling, through gestures such as raising his arms, and through a variety of other behaviors. As soon as he is mobile he can regulate proximity by approaching or following his mother, and he can achieve contact by climbing up on her and can maintain contact by clinging. His proximity- seeking behaviors soon become organized on a goal-corrected basis 
and, before long, organized in accordance with a plan in which the set-goal is constant but the techniques for achieving it are flexible.

However important attachment behavior is to the child and maternal care behavior to the mother, mother-infant interaction does not, of course, have close physical contact as an inevitable outcome. The predictable outcome is that proximity is maintained within limits reasonably approximating the set-goal, and in any given situation there is a dynamic equilibrium between proximity-seeking behavior and behavior with an outcome antithetical to proximity. The child's attachment behavior has proximity as its set-goal, but other behavior, such as exploratory behavior and play, tends to lead him to decrease proximity or to have proximity as an irrelevant consideration. The mother's "retrieval" behavior has proximity as its set-goal, but she has other set-goals, related to her housekeeping role, other children, husband, and outside activities, which compete with maternal care. Within the rough limits specified by his set-goal for proximity to his mother, the child may be attracted by complex or novel features of his animate or inanimate environment to explore or to play. If his explorations lead him beyond the set-goal limits, either his mother's retrieving behavior may be activated, or he himself will turn to seek greater proximity to her, or both. If in the course of her other activities his mother increases distance from him, he may follow her, or he may call to her to come to him, or indeed, she may spontaneously return to take him with her. Both persons have at their disposal a variety of behaviors with which their reciprocal set-goals can be implemented.

The activating conditions of attachment behavior differ in intensity, and so does each form of behavior. Approach behavior may be activated either by distance which exceeds the set-goal or by alarm. Alarm is an intense activator and is likely to evoke very rapid locomotion, in contrast to the leisurely approach likely under less intense circumstances. Furthermore, as the activating conditions become more intense, different forms of behaviors may be elicited. The alarmed child may scream in addition to approaching. The set-goal itself may change with increases in intensity of activation of attachment behavior. Whereas low-intensity behavior may be terminated merely by sight or sound of the mother-or by some kind of reassurance that she is nearby or likely soon to return-high intensity behavior has close physical contact with the mother as its set goal. Consequently, no simple scale of intensity of attachment behavior exists.

The child's own state may alter his set-goal. Physical contact tends to be the set-goal when the child is fatigued, ill, hungry, or in pain or discomfort. Certain environmental conditions may activate high-intensity behavior. In addition to alarm (caused by sudden changes of stimulus level, by strange objects, or by strange situations), rebuffs by other adults or by other children may cause the child to seek his mother's proximity. Finally, the whereabouts and behavior of the mother herself influence the form and intensity of attachment behavior-whether she is present or absent, departing or returning, and whether she accepts or rebuffs the child's overtures. Thus the intensity of attachment behavior is situationally determined, at least in part, and the tolerable distance specified by the set-goal differs from one set of circumstances to another.

Because of the diversity of attachment behavior and its differential arousal in different situations, there can be no simple criterion of attachment. Bowlby suggests that five main classes of behavior should be considered in any attempt to assess the attachment behavior of a 
child: (a) behavior that initiates interaction, such as greeting, approaching, touching, embracing, calling, reaching, and smiling; (b) behavior in response to the mother's interactional initiatives that maintains interaction (the above behaviors plus watching); (c) behavior aimed to avoid separations, such as following, clinging, and crying; (d) exploratory behavior, as it is oriented with reference to the mother; and (e) withdrawal or fear behavior, especially as it is oriented with reference to the mother.

Bowlby thus presents a behavioral model which is obviously testable, both in terms of exploring conditions which shift set-goals and of identifying individual differences in regard to the tolerable range of set-goals. But let us return to consider his four phases of development, for Phase 3 has both antecedents and consequents.

\section{Phase 1: Orientation and signals without discrimination of figure}

The infant during his first few weeks, despite his inability to discriminate one person from another, behaves in characteristic ways to people. He responds to anyone in his vicinity by orienting, tracking with his eyes, grasping, smiling, reaching, and by ceasing to cry on hearing a voice or seeing a face. The neonate is equipped with a number of behavioral systems, ready to be activated. Each system is already biased so that it is activated by stimuli falling within a broad range, terminated by stimuli falling within other broad ranges, and is strengthened or weakened by stimuli of yet other kinds. Despite the fact that the stimuli that activate and terminate these behavioral systems are discriminated only roughly, there is a marked bias toward responding in special ways to stimuli that commonly emanate from human beings-to the sound of the human voice, the sight of the human face, and the tactile and kinesthetic stimuli arising from the human arms and body.

Just as Piaget ([1936] 1952) suggests that the original schemata are little less fixed than reflexes, Bowlby suggests that these original biases are manifested through behaviors which resemble fixed-action patterns. There is no implication that the infant, in this stage, has proximity as a set-goal even through his behaviors have the predictable outcome of maintaining proximity.

After a review of the relevant literature pertaining to visual orientation, Bowlby concludes that the infant has an in-built bias toward looking at certain patterns in preference to others and at things that move; that this bias predisposes him in the ordinary expectable environment to pay special attention to the human face and to track it when it moves; that through perceptual learning the familiar comes to be distinguished from the strange; that there is an in-built bias to approach the familiar and, later, to withdraw from the strange; and that the feedback of consequences may augment or diminish sequences of orientation behavior. It is not necessary to invoke food as a reinforcer of the baby's orientation to his mother. It is more likely that the more he watches her, the more likely she is to approach him and to gesture, talk, pat, and hug him and these behaviors reinforce his tendency to watch her.

Similar reviews of the literature on head turning, sucking, grasping, clinging, reaching, smiling, babbling, and crying elucidates the infant's initial response biases, the signal function of his behavior in eliciting responses from human caretakers, and the way in which the feedback from 
caretakers serves variously to terminate the behavior in question, or to augment (or diminish) its likelihood of recurring, and gradually to restrict the effective stimuli to those of human origin and eventually (in most cases) to the mother figure and to a few other special figures.

Phase 2: Orientation and signals directed toward one or more discriminated figures.-In this phase the infant behaves in the same friendly way toward people as he did in Phase 1 but in more marked fashion to his mother than to others. Bowlby's account of this phase, and the next, is based largely upon Ainsworth's (1963, 1964, 1967) account. The baby displays differential behavior to his mother's voice (Wolff 1963); he stops crying differentially according to who holds him; he cries differentially when his mother departs as versus other people; he smiles and vocalizes differentially; he maintains a differential visual-postural orientation to his mother; and his greeting responses are differential. Following both Ainsworth (1967) and Schaffer and Emerson (1964), Bowlby acknowledges that the baby can behave differentially toward other familiar figures soon after, or (according to Schaffer and Emerson) perhaps even before, he responds differentially to his mother-and his objects include persons who have had no responsibility for reducing his basic drives or for fulfilling his essential needs.

Phase 3: Maintenance of proximity to a discriminated figure by means of locomotion as well as by signals.-With the onset of locomotion, the baby not only shows differential behaviors such as approaching, following, climbing upon, exploring, clinging to the mother in preference to others, and using her as a secure base from which to explore and as a haven of safety to which to return, but also his behavior becomes organized on a goal-corrected basis. Previously, his discrimination and differential behavior could scarcely indicate "attachment," but now "his attachment to his mother is . . . evident for all to see." The dynamic equilibrium between proximity-seeking behaviors and behaviors antithetic to proximity seeking is characteristic of mother-infant interaction in this phase. Further, the infant in this phase maintains proximity to an attachment figure by means of a more or less primitive cognitive map. Within that framework, the mother comes sooner or later to be conceived of as an object, independent, persistent in time and space, and moving more or less predictably in a time-space continuum (cf. Piaget [1937] 1954). Thus the baby's set-goals tend to be regulated in part by his expectations of his mother's behavior and whereabouts.

Phase 4: Formation of a reciprocal relationship.-Although previously the baby could to some extent predict his mother's movements and adjust his own to them, he could not understand the factors which influenced these and could not plan measures to change her behavior. Gradually, ho-Never, he comes to infer something about his mother's set-goals and about the plans she is adopting to achieve them. Then he can begin to attempt to alter her set-goals toward a closer fit with his own, through techniques of request or persuasion, rather than merely adjusting his set-goal to suit hers. In discussing the growth of a "goal-corrected partnership" of this sort, Bowlby refers to Piaget (see Flavell 1963). To frame a plan the goal of which is to change the set-goal of another's behavior requires considerable cognitive competence, including being able to see things from another's point of view. The child's earliest attempts at this can only be primitive and often incompetent, handicapped as the child is by what Piaget calls "egocentrism." Meanwhile, the child may be facilitated or hampered in his development by his parents' behaviors-the extent to which they clarify or dissemble about their set-goals, or encourage or discourage the child from taking cognizance of them. 
At first, and throughout the pre-locomotor period, the responsibility for maintaining infant-mother proximity is the mother's. The baby may signal, but the mother is responsible for responding to his signals with an increase or decrease in maternal care behavior. Even though the baby, once mobile, strongly tends to seek proximity, he is still not very competent to do so, and he tends to explore without much discrimination or judgment about dangers; therefore the responsibility still remains largely with the mother. Gradually, as the child's judgment improves-at about age 4 and perhaps about the beginning of Phase 4-proximity is maintained as much by the child as by mother. It is not for many years in the human species that the maintenance of proximity to parents is almost entirely the responsibility of the offspring.

Bowlby acknowledges a great gap between the plans made by an older child or adult achieving his attachment goals and the way in which attachment behavior is organized in the first year of life. The more sophisticated manifestations of attachment behavior are organized as plans, but nevertheless these have the same set-goals as does infantile attachment behavior-maintaining proximity, reducing distance, and/or engaging in social interchange. Attachment behavior persists throughout the whole life span. It may persist toward early attachment figures, and indeed usually does, but new figures are also selected. The kind of experience the person has had in his earlier attachments and the kind of competence he has achieved in perceiving the set-goals of another and in bringing them into harmony with his own will have a crucial bearing on his success in maintaining proximity and communication with new figures.

In regard to infant-mother attachment, Bowlby reiterates the view stated in 1958 that the infant has a bias toward monitory-toward attaching himself especially to one figure, usually his mother. He suggests that the infant's own mother is most likely to be biased toward responding to the infant; her hormonal state following his birth predisposes her to be especially responsive to the stimuli emanating from the infant. Nevertheless, infants may very quickly attach themselves to figures in addition to the mother. He cautions that these figures are not entirely interchangeable and that under conditions of heightened attachment behavior one (usually the mother) is likely to be preferred to others. He suggests that playmates should not be considered as attachment figures. Under conditions when attachment behavior is of low intensity, the child may seek interaction with a playmate; but when conditions heighten attachment behavior, he tends to seek an attachment figure. On the other hand, the roles of these figures may overlap to some extent. The mother may sometimes be a playmate, and the playmate may, if occasion demands it, fulfill te role of attachment object (cf. Freud \& Dann 1951). Inanimate objects may come to have certain components of attachment behavior directed toward them because the natural object is unavailable. Like the principal attachment figure, the substitute object-pacifier, thumb, cuddly toy is most likely to be sought when the child is tired, ill, or distressed.

Finally, let us make brief reference to deviant behavior, which can be comprehended in Bowlby's formulation. Perhaps the central issue refers to species-characteristic behaviors which fail to achieve a functional consequence. The literature of animal behavior yields many instances of behavioral systems, which are unimpaired in form and achieve their characteristic predictable outcome, but which are nonfunctional because of being directed toward a nonfunctional object. Familiar examples include precocial birds imprinted on inanimate objects or members of other species, and dogs and monkeys who become attached to inanimate 
surrogates. These anomalies clearly result from the unavailability of the functionally appropriate object at a critical phase of development. In other instances the behavioral system itself may not be in functionally effective order because of developmental anomalies of genetic or environmental origin. The environmental anomalies are "the price to be paid for flexibility" and occur, as the preceding examples suggest, when crucial learning takes place in an environment too different from the environment to which the behavioral system in queston was evolutionarily adapted. Further human examples may be found in the literature on long-term maternal deprivation and on homosexuality.

Bowlby acknowledges that certain behavioral systems, such as the food-intake system must be in reasonably functional order if the individual is to survive, but the systems responsible for sexual and parental behavior need not be. These latter behaviors are described as the product of a large number of component behavioral systems organized in very special ways, much of the development of which takes place while the individual is still immature. "There are plenty of occasions when an atypical environment can divert them from developing on an adaptive course." It is clear that there is a bridge from the ethologically oriented view to the psychoanalytic literature and that the modification in psychoanalytic theory which Bowlby proposes does not divide it from the extensive knowledge of pathological deviations which has developed within the context of the parent theory.

The model which Bowlby proposes-incorporating control systems theory with ethological principles-makes it possible to view man's attachment behavior in an evolutionary context and as comparable to attachment behavior in other species, without minimizing the complexity or flexibility of mature attachment behavior in the human. Provided development occurs in an environment of evolutionary adaptedness, the set-goal is essentially the same across species, although the means may differ. It is the set-goal, especially, which is relatively stable environmentally, whereas the attachment behaviors through which it is achieved have more lability. His model also takes into account a transformation of the infant's relatively plan-governed attachment behavior-a transformation which neither forces adult behavior into an oversimplified infantile mold nor attributes to the infant those processes, experiences, or objectives which are beyond the likely limits of his equipment.

His model is interactional throughout. The infant's initial equipment, genetically programmed as it is, develops through his interaction with his environment. The person is always viewed in a social context with his attachment behaviors interlocking with reciprocal behaviors of others; those of the infant are in inevitable interaction with the reciprocal behaviors of the mother figure. In the larger view, the infant-mother pair, coupled though they are by reciprocally interacting behavioral systems, are perceived in a wider environmental context with behaviors drawing them apart held in dynamic balance with behaviors drawing them together.

The differences between Bowlby's formulation and my views are minor, consisting only of slight differences in emphasis. Therefore the ethological position which Bowlby represents can most expediently be discussed in the next section, which will reexamine some of the issues in this review and compare the several theoretical approaches in respect to them.

\section{DISCUSSION}


"Object relations," "dependency," and "attachment" are concepts which, although overlapping, have developed in different theoretical traditions and have focused from the beginning upon different sets of problems in different contexts. The chief point of overlap is, of course, concern with the origins and development of the infant's first interpersonal relationships relationship with his mother or mother figure. Recently there has been a tendency toward convergence of the several major theoretical traditions upon this point of overlap. Such a convergence holds great promise for future advances in understanding of the early development of social relations and hence of personality development.

Each tradition has tied to it, more or less loosely, extensive bodies of empirical "facts," some of which are highly relevant to the origins and development of interpersonal relations, despite the fact that systematic research into the infant's relations has barely begun. These facts are now scattered and specific to the discipline in the context of which they were originally collected; consequently, it is impossible for them to be comprehended by any one theorist. The intertheoretical dialogue which has begun, and which is reflected in this review, should lead not only to a gradual integration of viewpoints but also to a conceptual reorganization of otherwise scattered facts.

There is a large and unwieldy, but nevertheless rich, accumulation of clinical facts which have been confirmed repeatedly and which require assimilation into any truly comprehensive theory. This body of facts, primarily linked to the psychoanalytic tradition, is little known to most experimentalists. On the other hand, there is a large experimental literature little known to clinicians but rich in facts relevant to an understanding of the social development of the infant. This literature is growing apace now that infancy has become such an active area of research. There is a third very large body of facts, roughly classifiable as biological, which is highly relevant to developmental psychology. This has been ignored by too many developmental psychologists in recent years.

The convergence which has activated an inter-theoretical dialogue has also brought to light sharp differences of opinion. Some of these differences may be genuine disagreements, and require resolution, presumably through critical research. Other differences probably reflect misunderstandings of terminological origin. Theorists from different traditions, even when they use the same terminology or terms which they consider to be synonymous, are often speaking of different things. Many of the points of difference in earlier sections appear, upon reflection, to be of this order. I now intend to reconsider some of these issues in the search for reconcilable misunderstandings, using an ethological orientation as a frame of reference.

An example of what is meant by a misunderstanding is the difference in meaning of the term "hereditarily determined" for Gewirtz (1969) and for ethologists, geneticists, and others working within an evolutionary frame of reference. Once a sharp distinction is drawn between "hereditarily determined" and "learned," it is difficult to perceive the possibility of the continuing influence of genetic biases in behavior which possesses a substantial degree of environmental lability.

Another misunderstanding which was touched upon previously hinges upon misconceptions 
about the phenomenon of extinction-misconceptions which very frequently lead others to misunderstand learning-theory formulations and which seem even to cause confusion within these formulations. According to Deese and Hulse (1967), no single mechanism of extinction can account for the phenomenon of the weakening of a response and reduction of its tendency to recur in situations in which reinforcement or cues which maintain the response are withdrawn. Nevertheless, they concluded, Pavlov's (1927) concept of response inhibition seems adequately to account for extinction following classical conditioning, and "frustration-competition" theory can deal with extinction following instrumental conditioning. According to both of these concepts, it is not that the underlying response tendency weakens and ultimately vanishes when the overt behavior tends to diminish and disappear. Rather, something is interposed which prevents the response from occurring-whether inhibition or some competing and incompatible response-but which affects the underlying response tendency or response strength little or not at all.

Such a concept of extinction resolves the paradox which Cairns failed explicitly to handle. According to this view, it is clear that when a child is separated from his object of attachment his attachment behavior directed toward that object may gradually diminish, perhaps because he directs attachment behavior toward substitute objects, perhaps because in frustration he emits responses incompatible with attachment behavior, or some combination of both. When later he is reunited with his mother, his attachment behavior toward her, although having been extinguished in the separation environment, may recur in full or little diminished strength, or indeed, heightened as a consequence of anxiety. On the other hand, the shorter or longer delays which occur with some children before attachment behavior reasserts itself can be viewed as due to behaviors, incompatible with or competing with attachment behavior, having been carried over from the separation period.

Bowlby (1960) used the term "detachment" to comprehend these incompatible behaviors, both in the separation situation and after reunion before the reappearance of attachment behavior. He suggested that detachment was due to a repressive defense. Ainsworth and Bell (in press) detected "detachment" in the making in such reunion responses as looking away, turning away, or moving away from the mother upon reunion, or ignoring her; these behaviors are clearly incompatible with attachment behavior. It would seem that the concept of detachment is in no way incompatible with the concept of extinction, that neither contradict the possibility of attachment behavior recurring after separation is over, and that both leave open the alternative that the detachment-the incompatible responses or even possibly the inhibition-can continue indefinitely to block the reemergence of attachment behavior.

Another misunderstanding revolves about the term "reinforcement." Despite the fact that "reinforcement" was from the beginning defined as the strengthening of a response so that it was more likely to recur, and a "reinforcer" as any stimulus, which, following a response, increased its strength, many fell into the practice of using "reinforcement" and "reinforcer" in the context of reward-and reward was frequently conceived in terms of drive reduction. The learning theorists themselves-and especially those who may be characterized as "drive theorists"-contributed to this misunderstanding. The operant conditioning theorists insisted that "reinforcement" should be restored to its original meaning. In acknowledgment of this insistence, an explanatory phrase began to emerge in the literature-"in the absence of 
conventional reward"-referring to reinforcement of a response (as, e.g., in "imprinting") which occurred when reduction of basic physiological drives such as hunger was in no way implicated.

It is now widely accepted that the formation of an attachment does not crucially depend upon drive reduction. The "secondary drive" explanation was plausible, long held, and hard to lay to rest. Among learning theorists the problem has been displaced to the question of what are "primary reinforcers." The list provided by Bijou and Baer (1965) emphasizes drive-reducing stimuli, although a few others are included. The fact that proximity and contact are not considered primary reinforcers by them, but are specified as secondary-acquired through having been associated with primary reinforcers-seems to be a carry-over of the earlier tendency to associate the term "primary" with basic physiological drives and to consider all else as secondary. Even Gewirtz, who has moved even further from a drive theory, expresses doubt that physical contact would be a primary reinforcer. Since the ethologically oriented perceive proximity to and contact with another figure to be the predictable outcome of even the earliest attachment behaviors-not only in the human but across many species-these seem at least primary, whether or not they are technically "primary reinforcers."

The ethologically oriented are concerned with ascertaining what conditions, both intraorganismic and environmental, are implicated in the activation of behavioral systems and what conditions terminate them once they have been activated. It is evident that different kinds and degrees of attachment behavior may be activated by conditions of different degrees of intensity and that different degrees of intensity of activation require different terminating conditions. Attachment behavior may thus be "strengthened" situationally, and this strengthening must be distinguished from "reinforcement" since it does not necessarily make the behavior more likely to recur.

Reinforcers may be confused in still other ways with activators and terminators. Environmental stimuli which activate attachment behavior have sometimes been identified by learning theorists as reinforcers. Thus, for example, the human face in movement is one of the most dependable activators of the smiling response in young infants. If the adult whose face activated the response reciprocates with a second smile, and the infant in response smiles again, is the adult's second smile a reinforcer? or merely an activator of the infant's second smile? or perhaps both? Environmental stimuli which terminate attachment behavior also have been sometimes identified as reinforcers. Thus, for example, if an infant is crying, physical contact with a person who picks him up is likely to terminate crying. Does physical contact also reinforce crying, making it more likely to occur again? It seems obvious to the learning theorist that it should have a reinforcing effect (cf. Etzel \& Gewirtz 1967). It seems equally obvious tothe ethologically oriented that this is not necessarily so, for so much seems to depend on the conditions which activated that cry and which may activate future cries, upon the other attachment behaviors available to the infant as alternatives, and also upon the whole context of mother-infant interaction. The ethologically oriented believe that some progress has been made in identifying activators and terminators of attachment behavior. It seems, however, that little progress has been made in identifying the reinforcers. As Gewirtz (1969) said, when discussing primary reinforcers, the matter of identification is an "empirical question." 
It would make sense to the ethologically oriented that different attachment behaviors not only might have different primary reinforcers but also might continue to be reinforced differentially by different sets of consequences. Thus, while the mother's smile might reinforce the infant's watching or smiling behavior, it is difficult to assume that it might reinforce his postural adjustment, or clinging, or crying, or following. Learning theory, by contrast, holds that reinforcers, whether primary or secondary, can be identified as such regardless of the particular behaviors which they may be found to reinforce (Meehl 1950).

An explanation of this difference may well be found in the distinction between experimental studies and naturalistic observation. In experimental studies, if it is found that the potential reinforcer introduced into the situation is, in fact, associated with an increased response probability, it is identified as a reinforcer without concern for whether it is primary or secondary or whether it would be likely to be a reinforcer in the "ordinary expectable environment." In naturalistic studies, on the other hand, activators and terminators (and reinforcers) are observed as they naturally occur and are all viewed as relevant to, and possibly as specific to, the particular behavioral system being observed.

Another concept which differs from "reinforcement," despite similarities, is "feedback." Both concepts refer to the consequences of the emission of a specific behavior which influence subsequent behaviors; in both, the effect depends upon the consequence being contingent upon the behavior; both may serve to strengthen the behavior and make it more likely to recur-by definition in the case of reinforcement. But feedback has broader implications than reinforcement. Feedback may serve to cue the next behavioral link in a chain of fixed-action patterns and may serve to reinforce the whole chain or any adjacent pair of behaviors in the chain. Feedback serves to sustain what Piaget ([1936] 1952) has termed a "circular reaction:" When the infant's behavior has an "interesting" consequence, he tends to repeat the behavior, at least approximately, in the more or less dimly recognized expectation that the consequence can be re-evoked. Repetitive behaviors of this sort have often been described as "self-reinforcing"-a term to which the operant conditioning theorists take exception as implying a redundancy. Feedback serves also to guide behavior toward a set-goal, and in this case it has much wider ramifications than reinforcement. Although behavioral sequences which are efficient means of achieving a set-goal may become habitual through frequent repetitions, any given sequence may be both successful and unique because the conditions under which it was evoked were unique. Although feedback may be positive, it is conceivable that presumably "reinforced" behavior may never occur again in this or in a similar context. In regard to behavior directed by a plan, flexibility in the selection of alternative means to the end, in accordance with situational variations, is a more salient consideration than reinforcement.

An even more crucial source of misunderstanding revolves about the distinction between attachment and attachment behavior. To be sure, attachments can be observed only through attachment behavior, and attachments undoubtedly grow by virtue of the fact that attachment behavior tends to be activated and terminated chiefly by specific figures. But the "attachment" relates to something inside the organism which may be distinguished from the behaviors which mediate it. Thus, attachment behavior may be heightened or intensified in a given situation without the necessary implication that the attachment becomes stronger. For example, a child 
may cling strongly when alarmed or be more "clingy" during a period of illness, without necessarily becoming more strongly attached. When the alarm is over, or when the period of illness is over-assuming that neither is prolonged or frequently repeated-the child is likely to behave much as he did previously. A person, child or adult, may be chronically "overdependent" and clingy. This does not imply that he is more attached to his specific objects of attachment than a person who is less dependent and less insecure.

Attachment is a synonym of love; dependency is not. Those in the psychoanalytic tradition use "object" and "love object" interchangeably in the context of attachment relationships. Presumably because lay readers understand "love" more readily than "attachment" both Bowlby (1965) and Ainsworth (1967) used "growth of love" in the titles of their publications rather than "growth of attachment." Harlow may have been facetious when he entitled his first paper on attachment behavior "The Nature of Love" (1958), but subsequently he has been consistent in referring to "affectional systems." If one asks: "Does a phobic wife who clings to her husband and constantly seeks his proximity love him more than a woman who is less neurotic and more competent loves her husband?" the answer is clearly, "No, not necessarily." Indeed, a clinician might infer that the phobic wife loves less than the healthier wife. A comparable question is: "Is the child who especially clings to his mother more attached to her than a child who clings less-or is he merely more insecure?" Nevertheless the clingy child and the clingy wife are clearly more dependent, even though they do not necessarily love more, and even though they are not more strongly attached. We must conclude that dependency and attachment are by no means identical, even though there is a great overlap in infancy between dependency behaviors and attachment behaviors.

The social learning theorists have acknowledged some of these effects in specifying that isolation, arousal, anxiety, and stress heighten dependency-or rather dependency behavior, for dependency is entirely a behavioral concept. But what of the strength of intensity of a specific relationship? Gewirtz (1969) specifies, and would probably be supported by Cairns (1966a), that the greater the number of behavior systems under the stimulus control of a particular person, the greater the degree of control; and the greater the number of settings in which the control operates, the stronger the attachment may be said to be. Something is stronger in such a relationship-perhaps "dependency;" certainly `being controlled by "-but is it attachment that is stronger? It certainly seems unlikely that it is "love" that is stronger.

In this context the psychoanalysts have made a valuable contribution. They have not been concerned so much with the quantitative dimension of object relations-stronger or weaker love or attachment-as with the qualitative variations among different object relations. How ambivalent is the relationship, what admixture of love and hate, and how well is the ambivalence resolved? How anxious is the relationship? How is it affected by the person's defenses against anxiety? All of these qualitative considerations have a bearing on the strength of attachment or dependency behavior. Both anxiety and ambivalence may heighten the behavior, while defenses against ambivalence and anxiety tend, in turn, to dampen down the behavior. If "attachment" refers to the "love" component of the relationship, rather than to the relationship as an amalgam of love, anger, and anxiety, then it is clear that the intensity of "attachment behaviors" is an obscure index of the attachment itself. Obviously, we are faced with an issue of definition. What do we mean by attachment? I lean to a definition which 
equates love and attachment. If such a definition is accepted, it is obvious that at the present time there is no set of indices $n$ terms of which strength or intensity of attachment can be assessed, for all behavioral indices are affected by ambivalence, anxiety, stress, separation, and isolation.

Gewirtz (1969), in an attempt to integrate the concepts of dependency and attachment, suggests that attachment is focused and directed toward one or a few specific figures, whereas dependency is generalized toward a class of persons. Immediately appealing though this distinction may be, it seems unlikely that this is the focal difference between dependency and attachment. According to both the psychoanalytically and ethologically oriented points of view, a prerequisite of attachment (or object relations) in comparison to pre-attachment (preobjectal) relations is that the object of attachment be conceived as having a permanent existence in space and time which is independent of present perception. Piaget ([1937] 1954) stresses the conceptual implications; the psychoanalysts speak of an "inner representation." This concept of inner representation of an object of attachment which transcends periods of absence and which does not wax and wane with gratifications provided or not provided by the object seems to be the crux of the difference between the social learning theorists and the others. The social learning theorists focus on the behavior and take it to be a dependable index of the relationship. So when the behavior becomes more intense the dependency (or attachment) relationship is assumed to be stronger, and when the behavior becomes less intense the relationship is assumed to have weakened. They do not concern themselves with anything "inside" which represents the relationship. The psychoanalytically and ethologically oriented theories imply that the attachment-the relationship-resides in the inner structure, which has both cognitive and affective aspects, and which affects behavior. To be sure, the existence of such an inner structure can be inferred only from behavior, but that it exists seems to me to be undeniable and demonstrable. Studies of responses to both separation from the attachment object and subsequent reunion with it yield unequivocal support to the proposition that attachments can and often do survive periods of absence, undiminished in strength, despite the fact that attachment behavior may diminish in strength during the period of absence.

The assertion of the significance of "inner structure" raises again the point that structural concepts are alien to learning theory. In contrast, throughout the biological sciences runs the persistent theme that organization and structure are fundamental to living material. Indeed, it is the persistence of structure in resistance to forces pressing toward change that is characteristic of life itself. It is only in death that the organism loses its characteristic structure -or the potential for developing it. Continuity of structure through and despite change is the focal biological theme.

Throughout both the phylogenetic and the ontogenetic accounts of development, a cardinal biological principle is that development takes place through transformations of structures already present, rather than through a process of accretion or replacement, and that these transformations take place through continuous organism-environment interaction. To me, therefore, the emphasis placed by the social learning theorists upon environmental control seems excessive, and their relative neglect of intra-organismic states and structural organizations seems a fault. It is not a necessary fault, however, for there seems to be no essential incompatibility between learning principles and the concept of an organism with 
internal structure and changing states. Indeed, this must be a matter of relative emphasis, for all theories acknowledge that behavior is a resultant of organism-environment interaction.

Gewirtz (1969) characterized Bowlby's and my formulations as "prelearning" theories. The implication is that both were primarily concerned with the origins of attachment and with specifying their "primary" features but that neither was concerned with subsequent modifications under environmental influences. It is true that neither has offered a detailed account of learning processes. Bowlby (1969) repeatedly refers to learning, even to "reinforcement," but the references are scattered, and there is no formal discussion of learning processes. But he is by no means concerned only with the "pre-learning" origins of attachment. On the contrary, a major focus of his theoretical orientation concerns that period of early childhood after goal-corrected behavior has appeared and when reciprocal partnership becomes a possibility. He stresses the hierarchical organization of behaviors during this later period-organization according to a "plan." Learning theories have not attempted to cope with hierarchical organization within their models; they tend, rather, to stress the simpler organization of chaining.

Both Bowlby (1969) and Ainsworth (1967) proposed that the behaviors through which attachment develops are comparable to Piaget's ([1936] 1952, [1937] 1954) initial schemata-indeed most of them are the same-and that they develop through processes homologous to those which Piaget described for cognitive development. Piaget's theory of sensorimotor development seems a viable alternative to current learning theories, and for some purposes it seems a better fit for the empirical facts relevant to the development of attachment. In laboratory studies the purpose is to subject the organism to stimulus control; hence these studies predispose toward a view of the organism as coming under environmental control. Naturalistic studies give another impression of development. As Piaget has implied, the infant seems to be learning to bring the environment under his control. The operant conditioners, through environmental manipulation, "shape" the animal's behavior. The baby, through manipulation of the environment, seems to be shaping his own behavior. This is perhaps more conspicuous in regard to physical objects which tend to be static and, in at least some cases, more manipulable and controllable than people are. Nevertheles, the infant cannot be considered a passive recipient of stimuli from social sources, but as active in his attempts to gain control of what happens to him. Indeed, as Cairns, Gewirtz, Bijou, and Baer have all acknowledged, the adults in his environment may come, to some extent, under his "control."

A point of great importance, to ethology and to many (but not all) of the formulations which have borrowed from ethology, is the concept of biological function. Although the biological functions of some systems, such as the food-intake system, seem readily apparent, those of other systems may be inferred only after careful study of the species and of other related species in their natural habitats-and sometimes only after pertinent experimentation has been carried out. Nevertheless, it is a central assumption that each species-characteristic behavioral system must have a biological function which facilitates species survival in the environment of evolutionary adaptedness and which accounts for the establishment through natural selection of the genetic coding basic to the behavioral system in question. The assumption that attachment behavior has a biological function of its own, quite independent of the functions of other systems such as food intake, gives it a primary role in human nature which is effectively missing in the other formulations considered in this review. For example, in all learning-theory 
formulations the fact that a child becomes attached to a mother figure is viewed as an accidental by-product, with consequences that are sometimes considered to be unfortunate and change-worthy.

Several times in the foregoing account, it has been implied that research methods influence the theoretical formulation associated with it. The reverse is also true. One heuristic claim of learning theory has been that it stimulates research. Through the hypothetico-deductive method testable hypotheses are derived from the theory, on the basis of which critical research can be designed. Ethology offers another research model, which, at least in its early stages of application, differs from learning theory, and which can also claim to stimulate significant research. Ethology proceeds through what Lewin (1951) termed "levels of successive approximation." First, in regard to any given species, the animal is observed naturalistically in its own habitat. Only after the main outlines of its behavioral repertoire have been observed, and after the relations between this repertoire and the natural habitat have been observed and evaluated, do refinements of scientific investigation begin. Several alternative lines of approach follow. The investigator may introduce experimental variations into the natural environment. He may observe a group of animals under conditions of captivity which preserve some of the chief features of the natural environment and especially an approximation o natural social grouping. Under these conditions, he may use either holistic and naturalistic observations or time-sample and coding techniques, or some combination of these. Or he may bring the animals into the laboratory in an attempt either to program their life histories, rearing them under artificial but specifically defined conditions, or to observe specific behaviors under controlled conditions. Regardless of his specific approach, however, he does not begin to frame hypotheses to be tested experimentally until after he has seen how the behavior in question fits into the animal's total behavioral repertoire, and how it appears to contribute to the survival of the species in the environment of evolutionary adaptedness.

For some decades developmental psychology tended to neglect naturalistic and longitudinal studies. This neglect was especially handicapping in the study of infant-mother attachment, in which the infant has to be studied over time in relation to a specific person, and preferably in his own family environment. The main theoretical accounts of this development-psychoanalytic and learning theories-framed what now seem to be naive hypotheses as deductions from their larger theoretical framework without adequate preliminary naturalistic exploration. The impact of an ethologically oriented view of development seems to be producing a dual effect on research into the early development of interpersonal relations-encouraging both naturalistic, longitudinal studies and an integration between these and studies using the experimental model. All the approaches reviewed here have a contribution to make to an integrated program of research and to the body of knowledge that would emerge therefrom. For such an integration to be maximally effective it is desirable that it be accompanied by some mutual accommodation and assimilation among the theoretical models themselves.

\section{Notes}

This paper was prepared in part while the author was a Fellow at the Center for Advanced Study in the Behavioral Sciences, and while receiving support through USPHS grant RO1 HD 01712. Gratitude is expressed to Silvia Bell, John Bowlby, and Stewart Hulse, whose 
constructive criticisms did much to improve this review, and to Bettye Caldwell and Henry Ricciuti, whose catalytic influence inspired this paper in its present form. Author's address: Department of Psychology, Johns Hopkins University, Baltimore, Maryland 21218.

1 A review of the research literature entitled "The Development of Infant-Mother Attachment," is being prepared by the present author and will appear in Review of Child Development Research, Vol. 3.

\section{References}

Ainsworth, M. D. The development of infant-mother interaction among the Ganda. In $B$. M. Foss (Ed.), Determinants of infant behaviour 11. London: Methuen; New York: Wiley, 1963. Pp. 67-112.

Ainsworth, M. D. Patterns of attachment behavior shown by the infant in Interaction with his mother. Merrill-Palmer Quarterly, 1964, 10, 51-58.

Ainsworth, M. D. S. Infancy in Uganda: infant care and the growth of love. Baltimore: Johns Hopkins University Press, 1967.

Ainsworth, M. D. S., \& Bell, S. M. Some contemporary patterns of mother-infant interaction in the feeding situation. In J. A. Ambrose (Ed.), The functions of stimulation in early post-natal development. London: Academic Press, in press.

Ainsworth, M. D. S., \& Bell, S. M. Attachment, exploration, and separation: illustrated by the behavior of one-year-olds in a strange situation. Child Development, in press.

Allport, G. W. Personality: a psychological interpretation. New York: Holt, 1937.

Ambrose, J. A. The concept of a critical period for the development of social responsiveness. In B. M. Foss (Ed.), Determinants of infant behaviour, II. London: Methuen; New York: Wiley, 1963. Pp. 201-225.

Balint, A. Love for the mother and mother-love. 1939. Translated in International Journal of Psycho-Analysis, 1949, 30, 251-259.

Balint, M. Early developmental states of the ego. Primary object love. 1937. Translated in International Journal of Psycho-Analysis, 1949, 30, 265-273.

Bandura, A. \& Walters, R. H. Social learning and personality development. New York: Holt Rinehart \& Winston, 1963.

Bateson, P. P. G. Relation between conspicuousness of stimuli and their effectiveness in the imprinting situation. Journal of Comparative and Physiological Psychology, 1984, 58, 407-411.

Bateson, P. P. G. The characteristics and context of imprinting. Biological Review, 1968, 41, 177-220.

Bell, S. M. The relationship of infant-mother attachment to the development of the concept of object-permanence. Unpublished doctoral dissertation, Johns Hopkins University, 1968.

Beller, E. K. Dependency and independence in young children. Journal of Genetic Psychology, 
1955, 87, 25--35.

Beller, E. K. Dependency and autonomous achievement striving related to orality and anality in early childhood. Child Development, 1957, 28, 287-314.

Beller, E. K. Exploratory studies of dependency. Transactions of New York Academy of Sciences, 1959, 21, 414-426.

Benedek, T. Personality development. In F. Alexander and H. Ross (Eds. ), Dynamic psychiatry. Chicago: University of Chicago Press, 1952. Pp. 63-113.

Bergman, P., \& Escalona, S. K. Unusual sensitivities in very young children. Psychoanalytic Study of the Child, 1949, 3/4, 333-352.

Bijou, S. W., \& Baer, D. M. Child development. Vol. 2. New York: Appleton Century-Crofts, 1965.

Bowlby, J. An ethological approach to research in child development. British Journal of Medical Psychology, 1957, 30, 230-240.

Bowlby, J. The nature of the child's tie to his mother. International Journal of Psycho-Analysis, 1958, 39, 350-373.

Bowlby, J. Separation anxiety. International Journal of Psycho-Analysis, 1960, 41, 69-113.

Bowlby, J. Child care and the growth of love. (2d ed.) London: Penguin, 1965.

Bowlby, J. Attachment and loss. Vol. 1. Attachment. London: Hogarth; New York: Basic Books, 1989.

Brody, S. Patterns of mothering. New York: International Universities Press, 1958.

Cairns, R. B. Attachment behavior of mammals. Psychological Review, 1988, 73, 409-426. (a)

Cairns, R. B. Development, maintenance, and extinction of social attachment behavior in sheep. Journal of Comparative and Physiological Psychology, 1968, 62, 298-306. (b)

Caldwell, B. M. The usefulness of the critical period hypothesis in the study of filiative behavior. Merrill-Palmer Quarterly, 1982, 8, 229-242.

Decarie, T. G. Intelligence and affectivity in early childhood. New York: International Universities Press, 1965.

Deese J., \& Hulse, S. H. The psychology of learning. (3d ed.) New York: McGraw-Hill, 1987.

Dobzhansky, T. The biological basis of human freedom. New York: Columbia University Press, 1958.

Dollard J., \& Miller, N. E. Personality and psychotherapy. New York: McGraw-Hill, 1950.

Erikson E. H. Growth and crises of the healthy personality. In M. J. E. Senn (Ed.), Symposium on the healthy personality. Suppl. 2. Transactions of the fourth conference on problems of infancy and childhood. New York: Josiah Macy Jr. Foundation, 1950. Pp. 91-146.

Erikson, E. H. Identity and the life cycle. New York: International Universities Press, 1959.

Escalona, S. K. Emotional development in the first year of life. In M. J. E. Senn (Ed.) Problems of infancy and childhood: Transactions of the sixth conference. New York: Josiah Macy 
Jr. Foundation, 1953. Pp. 11-92.

Escalona, S. K., Leitch, M. et al. Early phases of personality development. Monographs of the Society for Research in Child Development, 1952, 17, (2, Serial No. 54 ).

Etzel B., \& Gewirtz, J. L. Experimental modification of caretaker-maintained high rate operant crying in a 6- and a 20-week-old infant. (Infans Tyrannotearus). Journal of Experimental Child Psychology, 1987, 5, 303-317.

Fairbairn, W. R. D. Psycho-analytic studies of the personality. London: Tavistock, 1952.

Fairbain, W. R. D. A critical evaluation of certain basic psycho-analytical conceptions. British Journal for the Philosophy of Science, 1956, 7, 49-80.

Ferenezi, S. Versuch einer Cenitaltheorie. Vienna: Internationale Psycholanalytische Verlag, 1924. (Republished in English: Thalassa. Translated by H. A. Bunker. Albany, N.Y., Psychoanalytic Quarterly, Inc., 1938. )

Flavell, J. H. The developmental psychology of Jean Piaget. Princeton, N.J.: Van Nostrand, 1963.

Freedman D. G. Personality development in infancy: a biological approach. In S. L. Washburn \& P. C. Jay (Eds. ), Perspectives on Human Evolution 1. New York: Holt, Rinehart \& Winston, 1968. Pp. 258-287.

Freud, A. The psychoanalytic study of infantile feeding disturbances. Psychoanalytic Study of the Child, 1948, 2, 119-132.

Freud, A. The mutual influence in the development of ego. Psychoanalytic Study of the Child, 1952, 7 42-50.

Freud, A. Psychoanalysis and education. Psychoanalytic Study of the Child, 1954, 9, 9-15.

Freud, A. Normality and pathology in childhood: assessments of development. New York: International Universities Press, 1965.

Freud, A., \& Dann, S. An experiment in group upbringing. Psychoanalytic Study of the Child, 1951, 8, 127-88.

Freud, S. Three essays on the theory of sexuality. Standard edition, VII. 1905. London: Hogarth, 1953. Pp. 125-245.

Freud, S. On narcissism: an introduction. Standard edition, XIV. 1914. London: Hogarth, 1957. Pp. 73-102.

Freud, S. Inhibitions, symptoms and anxiety. Standard edition, $X X$. 1928. London: Hogarth, 1959. Pp. 87-172.

Freud, S. Female sexuality. Standard edition, XXI. 1931. London: Hogarth, 1961. Pp. 225-243.

Freud, S. An outline of psychoanalysis. London: Hogarth, 1938.

Gesell, A., \& Ilg, F. L. Infant and child care in the culture of today. New York: Harper, 1943.

Gewirtz, J. L. Succorance in young children. Unpublished doctoral dissertation, State University of Iowa, 1948. 
Gewirtz, J. L. A program of research on the dimensions and antecedents of emotional dependence. Child Development, 1958, 27, 205-221.

Gewirtz, J. L. A learning analysis of the effects of normal stimulation privation and deprivation on the acquisition of social motivation and attachment. In B. M. Foss ( Ed. ), Determinants of infant behaviour. London: Methuen; New York: Wiley, 1961. Pp. 213-290.

Gewirtz, J. L. Mechanisms of social learning: some roles of stimulation and behavior in early human development. In D. A. Goslin ( Ed. ), Handbook of socialization theory and research. Chicago: Rand McNally, 1969. Pp. 57-212.

Greenacre, P. Considerations regarding the parent-infant relationship. International Journal of Psycho-Analysis, 1960, 41, 571-584.

Harlow, H. F. The nature of love. American Psychologist, 1958, 13, 873-685.

Harlow, H. F. The development of affectional patterns in infant monkeys. In B. M. Foss ( Ed. ), Determinants of infant behaviour. York: Wiley, 1981. Pp. 75-97.

Harlow, H. F. The maternal affectional system. In B. M. Foss ( Ed. ), Determinants of infant behaviour II. London: Methuen; New York: Wiley, 1963. Pp. 3-34.

Harlow, H. F., \& Zimmermann, R. R. Affectional responses in the infant monkey. Science, 1959, 130, 421-432.

Hartmann, H. Ego psychology and the problem of adaptation. 1939. New York: International Universities Press, 1958.

Hartmann, H.; Kris, E.; \& Loewenstein, R. M. Comments on the formation of psychic structure. Psychoanalytic Study of the Child, 1948, 2, 11-38.

Hartmann, H.; Kris, E.; \& Loewenstein, R. M. Notes on the theory of aggression. Psychoanalytic Study of the Child, 1949, 3/4, 10-38.

Hartup, W. W. Dependency and independence. In H. W. Stevenson ( Ed. ), Child psychology: the sixty-second yearbook of the National Society for the Study of Education, Part I. Chicago: University of Chicago Press, 1983. Pp. 333-363.

Heathers, G. Emotional dependence and independence in nursery school play. Journal of Genetic Psychology, 1955, 87, 37-57.

Hinde, R. A. Animal behaviour: a synthesis of ethology and comparative psychology. New York: McGraw-Hill, 1988.

Hoffer, W. Mouth, hand and ego integration. Psychoanalytic Study of the Child, 1949, 3/4, 4956.

Hoffer, W. Development of the body ego. Psychoanalytic Study of the Child, 1950, 5, 18-23.

Kagan, J., \& Moss, H. A. Birth to maturity. New York: Wiley, 1962.

Kaufman, I. C., \& Rosenblum, L. A. Depression in infant monkeys separated from their mothers. Science, 1987, 155, 1030-1031.

Klein, M. Some theoretical conclusions regarding the emotional life of the infant. In M. Klein, 
P. Heimann, S. Isaacs, \& J. Riviere, Developments in psychoanalysis. London: Hogarth, 1952. Pp. 198-236.

Paris, E. Some comments and observations on early autoerotic activities. Psychoanalytic Study of the Child, 1951, 6, 95-118.

Kris, E. Neutralization and sublimation: observations on young children. Psychoanalytic Study of the Child, 1955, 10, 308.

Levy, D. M. Maternal overprotection. New York: Columbia University Press, 1943.

Lewin, K. Principles of topological psychology. New York: McGraw-Hill, 1938.

Lewin, K. Field theory in social science: Selected theoretical papers. D. Cartwright ( Ed. ), New York: Harper, 1951.

Lorenz, K. Companionship in bird life. 1935. In Claire H. Schiller ( Ed. ), Instinctive behavior. New York: International Universities Press, 1957, Pp. 83-118.

Maccoby, E. E., \& Masters, J. C. Attachment and dependency. In P. Mussen (Ed.), Carmichael's manual of child psychology, in press.

Mahler, M. S. On child psychoses and schizophrenia: autistic and symbiotic infantile psychoses. Psychoanalytic Study of the Child, 1952, 7, 288-305.

Mahler, M. S. Thoughts about development and individuation. Psychoanalytic Study of the Child, 1983, 18, 307-324.

Mahler, M. S. On the significance of the normal separation-individuation phase: with reference to research in symbiotic child psychosis. In M. Schur (Ed.), Drives affects and behavior. Vol. 2. New York: International Universities Press, 1965. Pp. 161-169.

Mahler, M. S. \& Gosliner, B. On symbiotic child psychosis. Psychoanalytic Study of the Child, 1955, 10, 195-212.

Mahler, M. S., \& LaPerriere K. Mother-child interaction during separation-individuation. Psychoanalytic Quarterly, 1985, 34, 483-198.

Meehl P. E. On the circularity of the law of effect. Psychological Bulletin, 1950, 47, 52-75.

Miller G. A.; Galanter, E.; \& Pribram, K. H. Plans and the structure of behavior. New York: Holt, Rinehart \& Winston, 1960.

Morgan, G, A., \& Ricciuti, H. N. Infants' responses to strangers during the first year. In B. M. Foss (Ed.), Determinants of infant behaviour IV. London: Methuen, 1968. Pp. 253-272.

Murray, H. A. Explorations in personality. New York: Oxford University Press, 1938.

Pavlov, I. P. Conditioned reflexes. Translated by G. V. Anrep. London: Oxford, 1927.

Piaget, J. The origins of intelligence in children. 1936. (2d ed.) New York: International Universities Press, 1952.

Piaget, J. The construction of reality in the child. 1937. New York: Basic Books, 1954.

Pribram, K. H. A review of theory in physiological psychology. Annual Review of Psychology, 1960, 11, 1-40. 
Rheingold, H. L. Controlling the infant's exploratory behavior. In B. M. Foss (Ed.), Determinants of infant behaviour II. London: Methuen; New York: Wiley, 1963. Pp. 171-178.

Robson, K. S. The role of eye-to-eye contact in maternal-infant attachment. Journal of Child Psychology and Psychiatry, 1967, 8, 13-25.

Sander, L. W. Issues in early mother-child interaction. Journal of the American Academy of Child Psychiatry, 1962, 1, 141-166.

Sander, L. W. Adaptive relationships in early mother-child interaction. Journal of the American Academy of Child Psychiatry, 1964, 3, 231-264.

Schaffer, H. R., \& Emerson, P. E. The development of social attachments in infancy. Monographs of the Society for Research in Child Development, 1964, 29, (3, Series No. 94).

Scott, J. P. The process of primary socialization in canine and human infants. Monographs of the Society for Research in Child Developments, 1963, 28, (1, Serial No. 85).

Sears, R. R. Dependency motivation. In M. R. Jones (Ed.), The Nebraska symposium on motivation. Lincoln: University of Nebraska Press, 1963. Pp. 25-64.

Sears, R. R.; Maccoby, E. E.; \& Levin, H. Patterns of child rearing. Evanston, Ill.: Row \& Peterson, 1957.

Sears, R. R.; Rau, L.; \& Alpert, R. Identification and child rearing. Stanford: Stanford University Press, 1965.

Sears, R. R.; Whiting, J. W. M.; Nowlis, V.; \& Sears, P. S. Some child rearing antecedents of dependency and aggression in young children. Genetic Psychology Monographs, 1953, 47, 135-234.

Sluckin, W. Imprinting and early learning. Chicago: Aldine, 1965.

Spencer-Booth, Y., \& Hinde, R. A. The effects of separating rhesus monkey infants from their mothers for six days. Journal of Child Psychology and Psychiatry, 1966, 7, 179-198.

Spitz, R. A. No and yes: On the genesis of human communication. New York: International Universities Press, 1957.

Spitz, R. A. A genetic field theory of ego formation. New York: International Universities Press, 1959.

Spitz, R. A. The first year of life. New York: International Universities Press, 1965. (a)

Spitz, R. A. The evolution of dialogue. In M. Schur (Ed.), Drives, affects and behavior. Vol. 2. New York: International Universities Press, 1965. Pp. 170-190. (b)

Stendler, C. B. Possible causes of over-dependency in young children. Child Development, 1954, 25, 125-146.

Walters, R. H., \& Parke, R. D. Social motivation, dependency and susceptibility to social influence. In L. Berkowitz (Ed.), Advances in experimental social psychology. Vol. 1. New York: Academic Press, 1964. Pp. 231-276. 